\title{
Synthesis of Indeno-Fused Derivatives of
}

\section{Quinolizinium Salts, Imidazo[1,2-a]pyridine,}

\section{Pyrido[1,2-a]indole, and 4H-Quinolizin-4-one via Benzannulated Enyne-Allenes}

\author{
Weixiang Dai, Jeffrey L. Petersen, and Kung K. Wang* \\ C. Eugene Bennett Department of Chemistry, West Virginia University \\ Morgantown, West Virginia 26506-6045
}

\section{Supporting Information}

\section{Table of Contents}

\section{Page}

S5 General Experimental Methods

S5 Experimental Procedure for Pyridinium Methanesulfonate 11b.

S5 Experimental Procedure for Pyridinium Methanesulfonate 11c.

S6 Experimental Procedure for

2-(Dimethylamino)-12-phenyl-7H-indeno[1,2-b]quinolizin-5-ium Methanesulfonate (15b). 
Experimental Procedure for

2-Methoxy-12-phenyl-7H-indeno[1,2-b]quinolizin-5-ium Methanesulfonate (15c).

S7 Experimental Procedure for Propargyl Methanesulfonate 18b.

S7 Experimental Procedure for Pyridinium Methanesulfonate 19b.

S7 Experimental Procedure for

2-(Dimethylamino)-12-(trimethylsilyl)-7H-indeno[1,2-b]quinolizin-5-ium

Chloride (21b).

S9-S10 $\quad{ }^{1} \mathrm{H}$ and ${ }^{13} \mathrm{C}$ NMR Spectra of Propargylic Alcohol 8.

S11-S12 $\quad{ }^{1} \mathrm{H}$ and ${ }^{13} \mathrm{C}$ NMR Spectra of Propargyl Methanesulfonate 9.

S13-S14 $\quad{ }^{1} \mathrm{H}$ and ${ }^{13} \mathrm{C}$ NMR Spectra of Pyridinium Methanesulfonate 11a.

S15-S16 $\quad{ }^{1} \mathrm{H}$ and ${ }^{13} \mathrm{C}$ NMR Spectra of Pyridinium Methanesulfonate 11b.

S17-S18 $\quad{ }^{1} \mathrm{H}$ and ${ }^{13} \mathrm{C}$ NMR Spectra of Pyridinium Methanesulfonate 11c.

S19-S20 $\quad{ }^{1} \mathrm{H}$ and ${ }^{13} \mathrm{C}$ NMR Spectra of

2-Amino-12-phenyl-7H-indeno[1,2-b]quinolizin-5-ium

Methanesulfonate (15a).

S21-S22 $\quad{ }^{1} \mathrm{H}$ and ${ }^{13} \mathrm{C}$ NMR Spectra of

2-(Dimethylamino)-12-phenyl-7H-indeno[1,2-b]quinolizin-5-ium

Methanesulfonate (15b).

S23-S24 $\quad{ }^{1} \mathrm{H}$ and ${ }^{13} \mathrm{C}$ NMR Spectra of

2-Methoxy-12-phenyl-7H-indeno[1,2-b]quinolizin-5-ium Methanesulfonate (15c).

S25-S26 $\quad{ }^{1} \mathrm{H}$ and ${ }^{13} \mathrm{C}$ NMR Spectra of Propargylic Alcohol 17a.

S27-S28 $\quad{ }^{1} \mathrm{H}$ and ${ }^{13} \mathrm{C}$ NMR Spectra of Propargyl Methanesulfonate 18a.

S29-S30 $\quad{ }^{1} \mathrm{H}$ and ${ }^{13} \mathrm{C}$ NMR Spectra of Propargyl Methanesulfonate $\mathbf{1 8 b}$. 
S31-S32 ${ }^{1} \mathrm{H}$ and ${ }^{13} \mathrm{C}$ NMR Spectra of Pyridinium Methanesulfonate 19a.

S33-S34 $\quad{ }^{1} \mathrm{H}$ and ${ }^{13} \mathrm{C}$ NMR Spectra of Pyridinium Methanesulfonate 19b.

S35-S36 $\quad{ }^{1} \mathrm{H}$ and ${ }^{13} \mathrm{C}$ NMR Spectra of

2-(Dimethylamino)-12-(1,1-dimethylethyl)-7H-indeno[1,2-b]quinolizin-5-ium

Chloride (21a).

S37-S38 $\quad{ }^{1} \mathrm{H}$ and ${ }^{13} \mathrm{C}$ NMR Spectra of

2-(Dimethylamino)-12-(trimethylsilyl)-7H-indeno[1,2-b]quinolizin-5-ium

Chloride (21b).

S39-S40 $\quad{ }^{1} \mathrm{H}$ and ${ }^{13} \mathrm{C}$ NMR Spectra of

11-Phenyl-6H-indeno[1,2- $d]$ imidazo[1,2- $a]$ pyridine (24).

S41-S42 $\quad{ }^{1} \mathrm{H}$ and ${ }^{13} \mathrm{C}$ NMR Spectra of Indole 31.

S43-S44 $\quad{ }^{1} \mathrm{H}$ and ${ }^{13} \mathrm{C}$ NMR Spectra of

12-Phenyl-7H-indeno[ $\left[1^{\prime}, 2^{\prime}: 4,5\right]$ pyrido[1,2- $\left.a\right]$ indole (32).

S45-S46 $\quad{ }^{1} \mathrm{H}$ and ${ }^{13} \mathrm{C}$ NMR Spectra of 2(1H)-Pyridinone 34.

S47-S48 $\quad{ }^{1} \mathrm{H}$ and ${ }^{13} \mathrm{C}$ NMR Spectra of

4,7-Dihydro-12-phenylindeno[2,1-g]quinolizin-4-one (35).

S49 Figure S1. ORTEP Drawing of the Crystal Structure of

2-Amino-12-phenyl-7 $H$-indeno[1,2-b]quinolizin-5-ium

Methanesulfonate (15a).

S50 Figure S2. ORTEP Drawing of the Crystal Structure of

2-(Dimethylamino)-12-phenyl-7H-indeno[1,2-b]quinolizin-5-ium

Methanesulfonate (15b). 
S51 Figure S3. ORTEP Drawing of the Crystal Structure of

2-Methoxy-12-phenyl-7H-indeno[1,2-b]quinolizin-5-ium Methanesulfonate (15c).

S52 Figure S4. ORTEP Drawing of the Crystal Structure of

2-(Dimethylamino)-12-(1,1-dimethylethyl)-7H-indeno[1,2-b]quinolizin-5-ium

Chloride (21a).

S53 Figure S5. ORTEP Drawing of the Crystal Structure of

11-Phenyl-6H-indeno[1,2- $d]$ imidazo[1,2-a]pyridine (24).

S54 Figure S6. ORTEP Drawing of the Crystal Structure of

4,7-Dihydro-12-phenylindeno[2,1-g]quinolizin-4-one (35). 
All reactions were conducted in oven-dried $\left(120^{\circ} \mathrm{C}\right)$ glassware under a nitrogen atmosphere. Diethyl ether was distilled from benzophenone ketyl. Compounds $\mathbf{6},{ }^{3 \mathrm{c}} \mathbf{1 6},{ }^{9} \mathbf{1 7 b},{ }^{9}$ $25,{ }^{10} \mathbf{3 0},{ }^{10}$ and $33^{10}$ were prepared according to the reported procedures. 4-Aminopyridine, 4(dimethylamino)pyridine, 4-methoxypyridine, $2.5 \mathrm{M}$ solution of butyllithium in hexanes, propargyl alcohol, $\mathrm{Pd}\left(\mathrm{PPh}_{3}\right)_{2} \mathrm{Cl}_{2}$, copper(I) iodide, methanesulfonyl chloride, 3,3-dimethyl-1butyne, (trimethylsilyl)ethyne, imidazole, tetrabutylammonium iodide, $1.0 \mathrm{M}$ solution of potassium $t$-butoxide in $t$-butyl alcohol were purchased from chemical suppliers and were used as received. Melting points were uncorrected. ${ }^{1} \mathrm{H}(270 \mathrm{MHz})$ and ${ }^{13} \mathrm{C}(67.9 \mathrm{MHz}) \mathrm{NMR}$ spectra were recorded in $\mathrm{CDCl}_{3}$ using $\mathrm{CHCl}_{3}\left({ }^{1} \mathrm{H} \delta\right.$ 7.26) and $\mathrm{CDCl}_{3}\left({ }^{13} \mathrm{C} \delta 77.00\right)$ as internal standards unless otherwise indicated.

Pyridinium Methanesulfonate 11b. To a solution of $9(186 \mathrm{mg}, 0.600 \mathrm{mmol})$ in $5 \mathrm{~mL}$ of methylene chloride was added dropwise a solution of 4-(dimethylamino)pyridine (73 mg, 0.60 $\mathrm{mmol}$ ) in $5 \mathrm{~mL}$ of methylene chloride. The reaction mixture was stirred at room temperature for $24 \mathrm{~h}$ and concentrated. The residue was washed with diethyl ether to give $259 \mathrm{mg}(0.600 \mathrm{mmol}$, $100 \%$ ) of $11 \mathrm{~b}$ as a viscous liquid: IR 1651, 1192, $765 \mathrm{~cm}^{-1} ;{ }^{1} \mathrm{H} \delta 8.64(2 \mathrm{H}, \mathrm{d}, J=7.9 \mathrm{~Hz})$, 7.46-7.57 (4 H, m), 7.29-7.42 (5 H, m), $6.51(2 \mathrm{H}, \mathrm{d}, J=7.9 \mathrm{~Hz}), 5.53(2 \mathrm{H}, \mathrm{s}), 3.07$ (6 H, s), $2.81(3 \mathrm{H}, \mathrm{s}) ;{ }^{13} \mathrm{C} \delta 156.2,141.6,131.8,131.7,129.0,128.7,128.5,128.3,125.5,123.5,122.6$, $107.7,93.0,88.4,87.9,83.7,47.5,40.1,39.5$.

Pyridinium Methanesulfonate 11c. To a solution of $9(30 \mathrm{mg}, 0.097 \mathrm{mmol})$ in $5 \mathrm{~mL}$ of methylene chloride was added dropwise a solution of 4-methoxypyridine (11 mg, $0.101 \mathrm{mmol})$ in $5 \mathrm{~mL}$ of methylene chloride. The reaction mixture was stirred at room temperature for $24 \mathrm{~h}$ and concentrated. The residue was washed with diethyl ether to give $41 \mathrm{mg}(0.097 \mathrm{mmol}, 100 \%)$ of 11c as a colorless solid: $\mathrm{mp} 133-134{ }^{\circ} \mathrm{C}$; IR $2216,1192,762 \mathrm{~cm}^{-1} ;{ }^{1} \mathrm{H} \delta 9.19(2 \mathrm{H}, \mathrm{d}, J=6.9$ 
Hz), 7.31-7.55 (9 H, m), $6.99(2 \mathrm{H}, \mathrm{d}, J=6.9 \mathrm{~Hz}), 5.86(2 \mathrm{H}, \mathrm{s}), 3.96(3 \mathrm{H}, \mathrm{s}), 2.78(3 \mathrm{H}, \mathrm{s}) ;{ }^{13} \mathrm{C}$

$\delta 171.1,145.7,131.9,131.7,129.3,128.9,128.7,128.5,128.4,125.7,123.2,122.6,113.2,93.0$, $89.8,87.9,82.7,57.8,49.9,39.5$.

\section{2-(Dimethylamino)-12-phenyl-7H-indeno[1,2-b]quinolizin-5-ium Methanesulfonate (15b). A}

solution of 11b (51 mg, $0.12 \mathrm{mmol}$ ) and triethylamine (12 mg, $0.12 \mathrm{mmol})$ in $10 \mathrm{~mL}$ of ethanol was stirred at room temperature for $72 \mathrm{~h}$. The solvent was removed and the residue was washed with diethyl ether to give $51 \mathrm{mg}(0.12 \mathrm{mmol}, 100 \%)$ of $\mathbf{1 5 b}$ as a yellow solid: compound becomes black at $228^{\circ} \mathrm{C}$ without melting; IR $1647,1195 \mathrm{~cm}^{-1} ;{ }^{1} \mathrm{H} \delta 9.62(1 \mathrm{H}, \mathrm{d}, J=7.6 \mathrm{~Hz})$, 9.39 (1 H, s), 7.61-7.71 (3 H, m), $7.55(1 \mathrm{H}, \mathrm{d}, J=7.7 \mathrm{~Hz}), 7.26-7.41(4 \mathrm{H}, \mathrm{m}), 7.07(1 \mathrm{H}, \mathrm{t}, J=$ $7.9 \mathrm{~Hz}), 6.43(1 \mathrm{H}, \mathrm{d}, J=8.2 \mathrm{~Hz}), 6.27(1 \mathrm{H}, \mathrm{d}, J=2.9 \mathrm{~Hz}), 4.22(2 \mathrm{H}, \mathrm{s}), 3.04(6 \mathrm{H}, \mathrm{s}), 2.87(3$ $\mathrm{H}, \mathrm{s}) ;{ }^{13} \mathrm{C} \delta 152.0,146.3,145.7,143.8,138.8,136.8,133.9,132.4,131.0,130.3,130.1,129.7$, $129.2,127.4,126.6,125.6,125.3,109.8,99.6,39.7,39.6,34.3$. Recrystallization of $\mathbf{1 5 b}$ from a mixture of dichloromethane and hexanes produced a crystal suitable for X-ray structure analysis. 2-Methoxy-12-phenyl-7H-indeno[1,2-b]quinolizin-5-ium Methanesulfonate (15c). A solution of 11c (150 mg, $0.358 \mathrm{mmol})$ and triethylamine (36 mg, $0.36 \mathrm{mmol})$ in $40 \mathrm{~mL}$ of ethanol was stirred at room temperature for $15 \mathrm{~h}$. The solvent was removed and the residue was washed with diethyl ether to give $150 \mathrm{mg}(0.358 \mathrm{mmol}, 100 \%)$ of $\mathbf{1 5 c}$ as a yellow solid: compound becomes black at $228{ }^{\circ} \mathrm{C}$ without melting; IR 1644, $1193 \mathrm{~cm}^{-1} ;{ }^{1} \mathrm{H} \delta 10.09(1 \mathrm{H}, \mathrm{s}), 9.99(1 \mathrm{H}, \mathrm{d}, J=7.7$ Hz), 7.69-7.78 (3 H, m), 7.64 (1 H, d, $J=7.9 \mathrm{~Hz}), 7.37-7.52(4 \mathrm{H}, \mathrm{m}), 7.14(1 \mathrm{H}, \mathrm{t}, J=7.8 \mathrm{~Hz})$, $6.87(1 \mathrm{H}, \mathrm{d}, J=3.0 \mathrm{~Hz}), 6.52(1 \mathrm{H}, \mathrm{d}, J=8.2 \mathrm{~Hz}), 4.39(2 \mathrm{H}, \mathrm{s}), 3.86(3 \mathrm{H}, \mathrm{s}), 2.92(3 \mathrm{H}, \mathrm{s}) ;{ }^{13} \mathrm{C}$ $\delta 163.8,148.0,146.9,144.5,140.3,136.4,136.2,133.1,132.3,131.9,130.5,130.1,129.2,127.9$, $127.7,125.8,125.6,114.4,103.2,56.6,39.6,34.8$. Recrystallization of $\mathbf{1 5 c}$ from a mixture of dichloromethane and hexanes produced a crystal suitable for X-ray structure analysis. 
Propargyl Methanesulfonate 18b. To a solution of 17b (164 mg, $0.72 \mathrm{mmol})$ and triethylamine (109 mg, $1.08 \mathrm{mmol})$ in $10 \mathrm{~mL}$ of methylene chloride at $-50{ }^{\circ} \mathrm{C}$ under a nitrogen atmosphere was added dropwise methanesulfonyl chloride (108 $\mathrm{mg}, 0.94 \mathrm{mmol})$. The reaction mixture was allowed to warm to room temperature and stirred for $1 \mathrm{~h}$ before $5 \mathrm{~mL}$ of water was introduced. The organic layer was separated, and the aqueous layer was back extracted with methylene chloride. The combined organic layers were washed with water, dried over $\mathrm{MgSO}_{4}$, and concentrated. The residue was purified by column chromatography (silica gel/ethyl acetate:hexanes $=1: 4)$ to give $196 \mathrm{mg}(0.64 \mathrm{mmol}, 89 \%)$ of $\mathbf{1 8 b}$ as a colorless liquid: IR 2232, 2159, 1367, $1177 \mathrm{~cm}^{-1} ;{ }^{1} \mathrm{H} \delta 7.41-7.50(2 \mathrm{H}, \mathrm{m}), 7.25-7.35(2 \mathrm{H}, \mathrm{m}), 5.12(2 \mathrm{H}, \mathrm{s}), 3.17(3 \mathrm{H}, \mathrm{s})$, $0.27(9 \mathrm{H}, \mathrm{s}) ;{ }^{13} \mathrm{C} \delta 132.4,132.2,129.1,128.3,126.1,124.0,102.7,99.4,87.9,84.4,58.4,39.3$, -0.1 .

Pyridinium Methanesulfonate 19b. To a solution of $18 \mathrm{~b}(26 \mathrm{mg}, 0.085 \mathrm{mmol})$ in $5 \mathrm{~mL}$ of methylene chloride was added dropwise a solution of 4-(dimethylamino)pyridine (10.4 mg, $0.085 \mathrm{mmol}$ ) in $5 \mathrm{~mL}$ of methylene chloride. The reaction mixture was stirred at room temperature for $24 \mathrm{~h}$ and concentrated. The residue was washed with diethyl ether to give $36 \mathrm{mg}$ ( $0.084 \mathrm{mmol}, 99 \%)$ of $\mathbf{1 9 b}$ as a colorless solid: compound becomes black at $162{ }^{\circ} \mathrm{C}$ without melting; IR 2158, 1652, $1194 \mathrm{~cm}^{-1} ;{ }^{1} \mathrm{H} \delta 8.61(2 \mathrm{H}, \mathrm{d}, J=7.4 \mathrm{~Hz}), 7.43-7.49(2 \mathrm{H}, \mathrm{m})$, 7.28-7.34 (2 H, m), $6.97(2 \mathrm{H}, \mathrm{d}, J=7.7 \mathrm{~Hz}), 5.48(2 \mathrm{H}, \mathrm{s}), 3.25(6 \mathrm{H}, \mathrm{s}), 2.79(3 \mathrm{H}, \mathrm{s}), 0.21(9$ $\mathrm{H}, \mathrm{s}) ;{ }^{13} \mathrm{C} \delta 156.6,141.9,132.5,132.4,129.1,128.4,125.7,123.5,108.1,103.0,98.9,88.3,83.2$, $47.8,40.3,39.5,0.0$.

\section{2-(Dimethylamino)-12-(trimethylsilyl)-7H-indeno[1,2-b]quinolizin-5-ium Chloride (21b). A}

solution of 19b (30 mg, $0.070 \mathrm{mmol})$ and triethylamine $(7 \mathrm{mg}, 0.07 \mathrm{mmol})$ in $10 \mathrm{~mL}$ of ethanol was heated under reflux for $48 \mathrm{~h}$. The solvent was removed in vacuo, and the residue was 
purified by column chromatography (neutral alumina/ethanol:methylene chloride $=1: 10$ ) to give $11 \mathrm{mg}(0.030 \mathrm{mmol}, 43 \%)$ of $\mathbf{2 1 b}$ as a yellow solid: $\mathrm{mp}>360{ }^{\circ} \mathrm{C}$; IR $1646,1235 \mathrm{~cm}^{-1} ;{ }^{1} \mathrm{H} \delta$ $10.16(1 \mathrm{H}, \mathrm{d}, J=7.6 \mathrm{~Hz}), 9.70(1 \mathrm{H}, \mathrm{s}), 7.93(1 \mathrm{H}, \mathrm{d}, J=7.6 \mathrm{~Hz}), 7.62(1 \mathrm{H}, \mathrm{d}, J=7.6 \mathrm{~Hz})$, 7.40-7.56 (3 H, m), 7.21 (1 H, dd, $J=7.6,2.9 \mathrm{~Hz}), 6.98(1 \mathrm{H}, \mathrm{d}, J=2.6 \mathrm{~Hz}), 4.15$ (2 H, s), 3.26 (6 H, s), $0.62(9 \mathrm{H}, \mathrm{s}) ;{ }^{13} \mathrm{C} \delta 157.1,151.4,147.0,146.6,139.2,138.2,132.6,131.2,130.5,127.7$, $126.7,125.9,125.3,109.2,103.2,40.1,34.5,2.6$. 


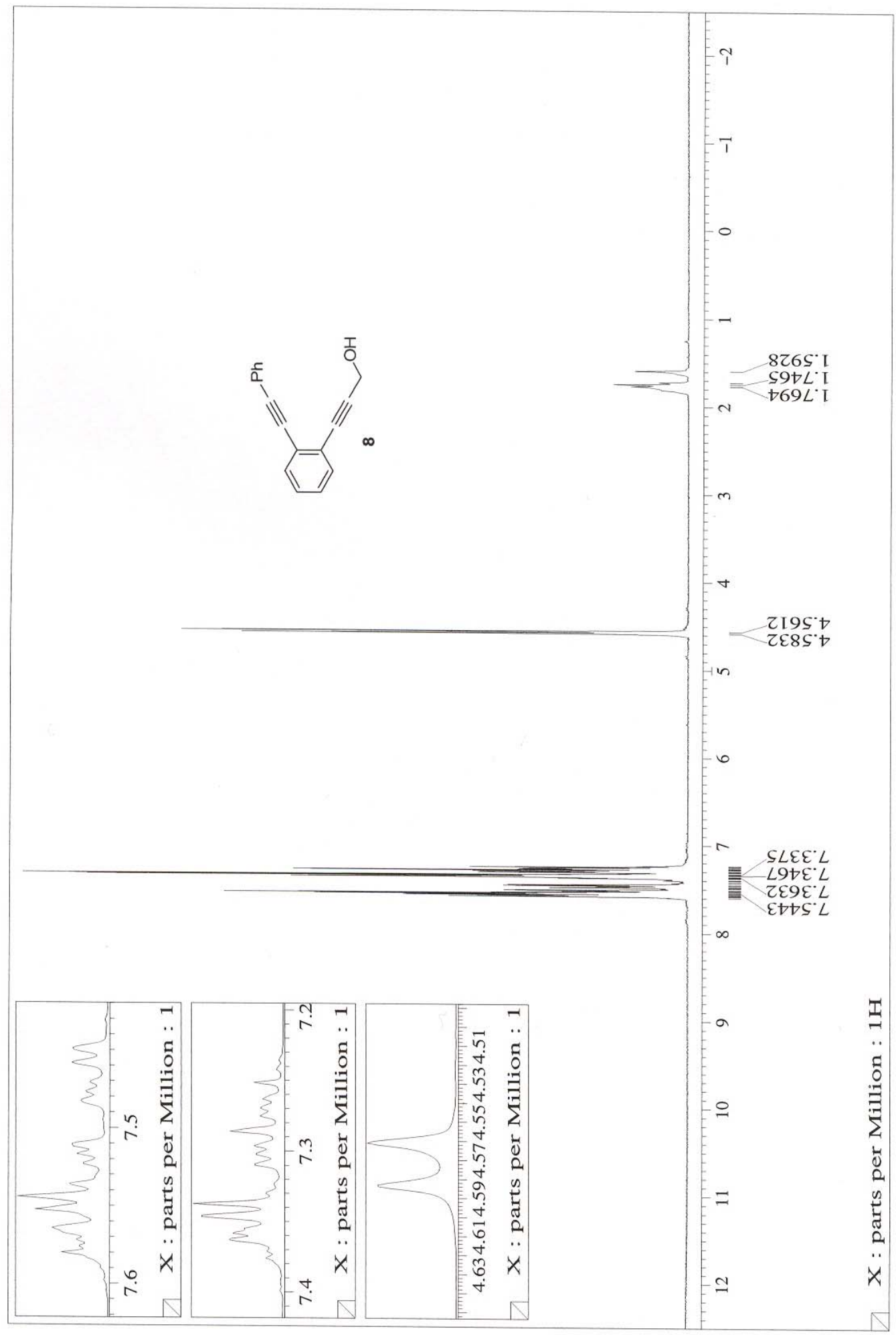




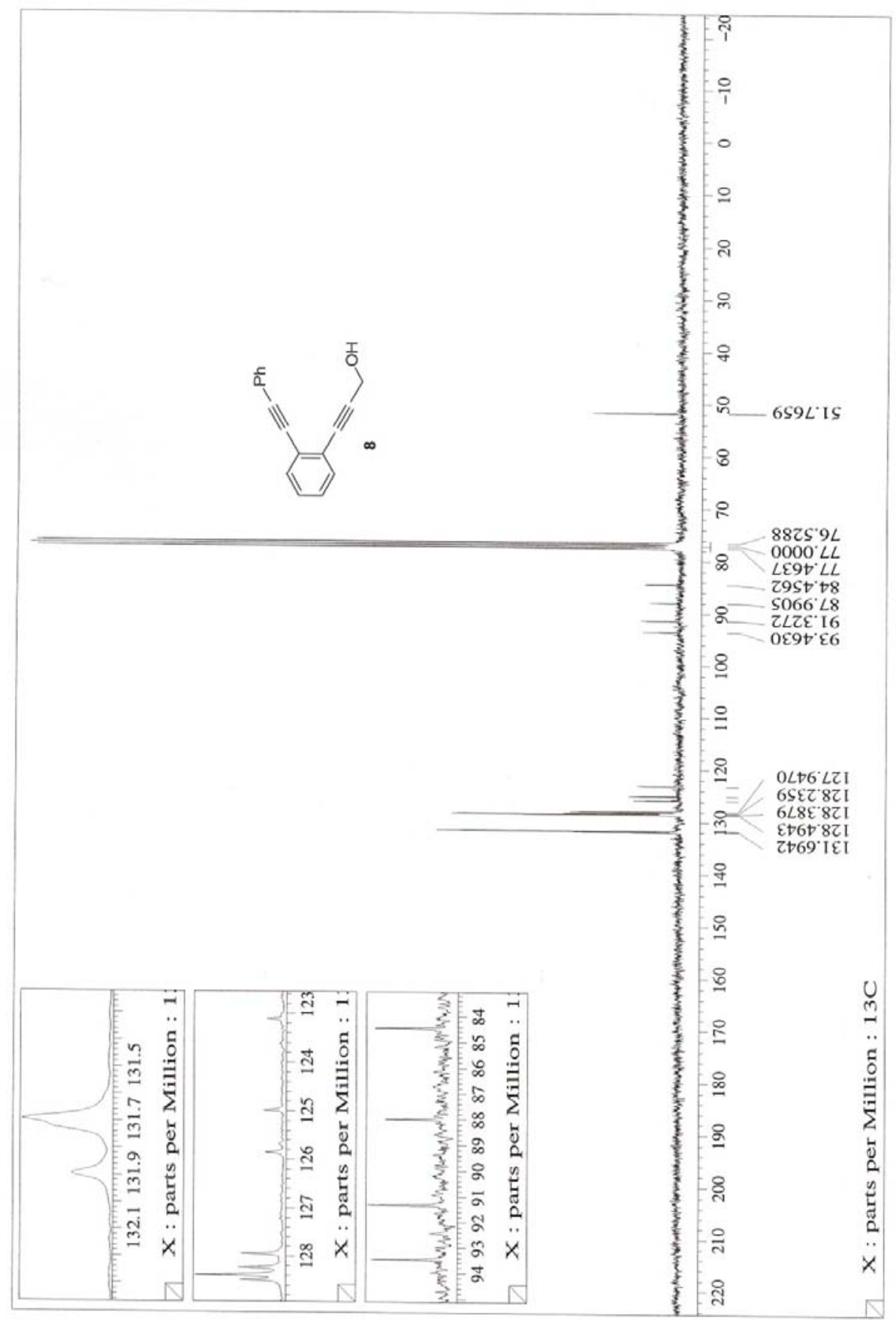




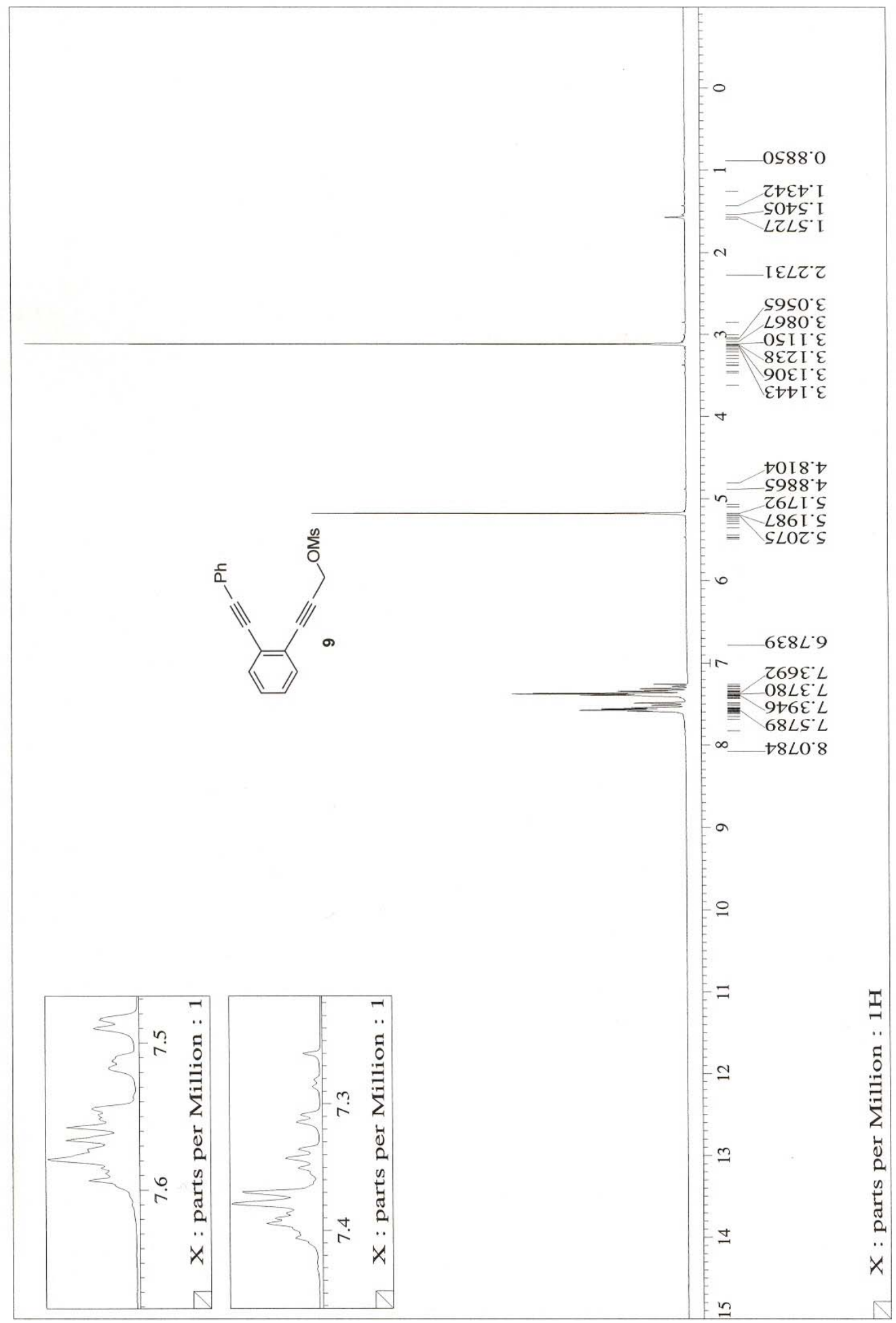




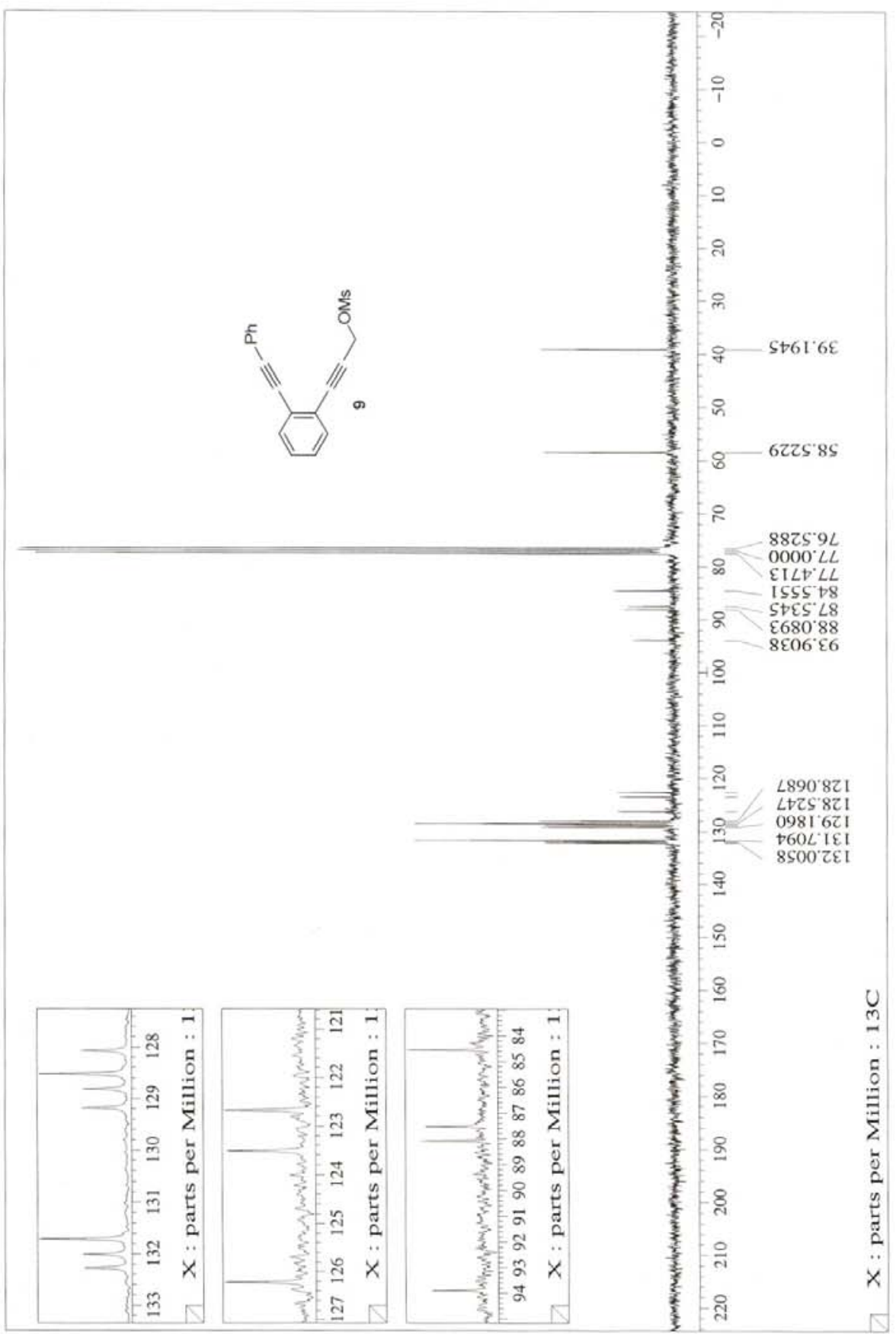


nomenty

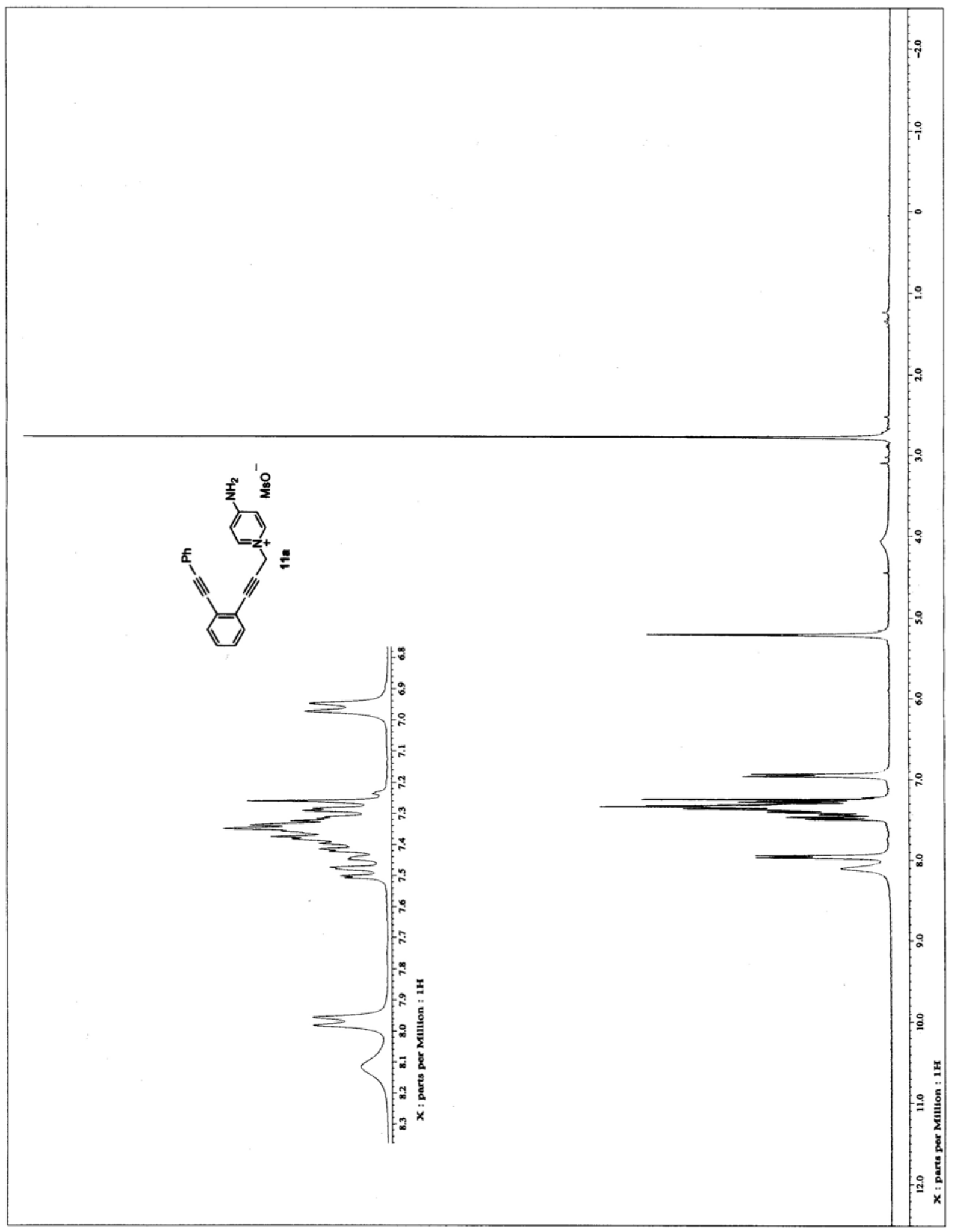




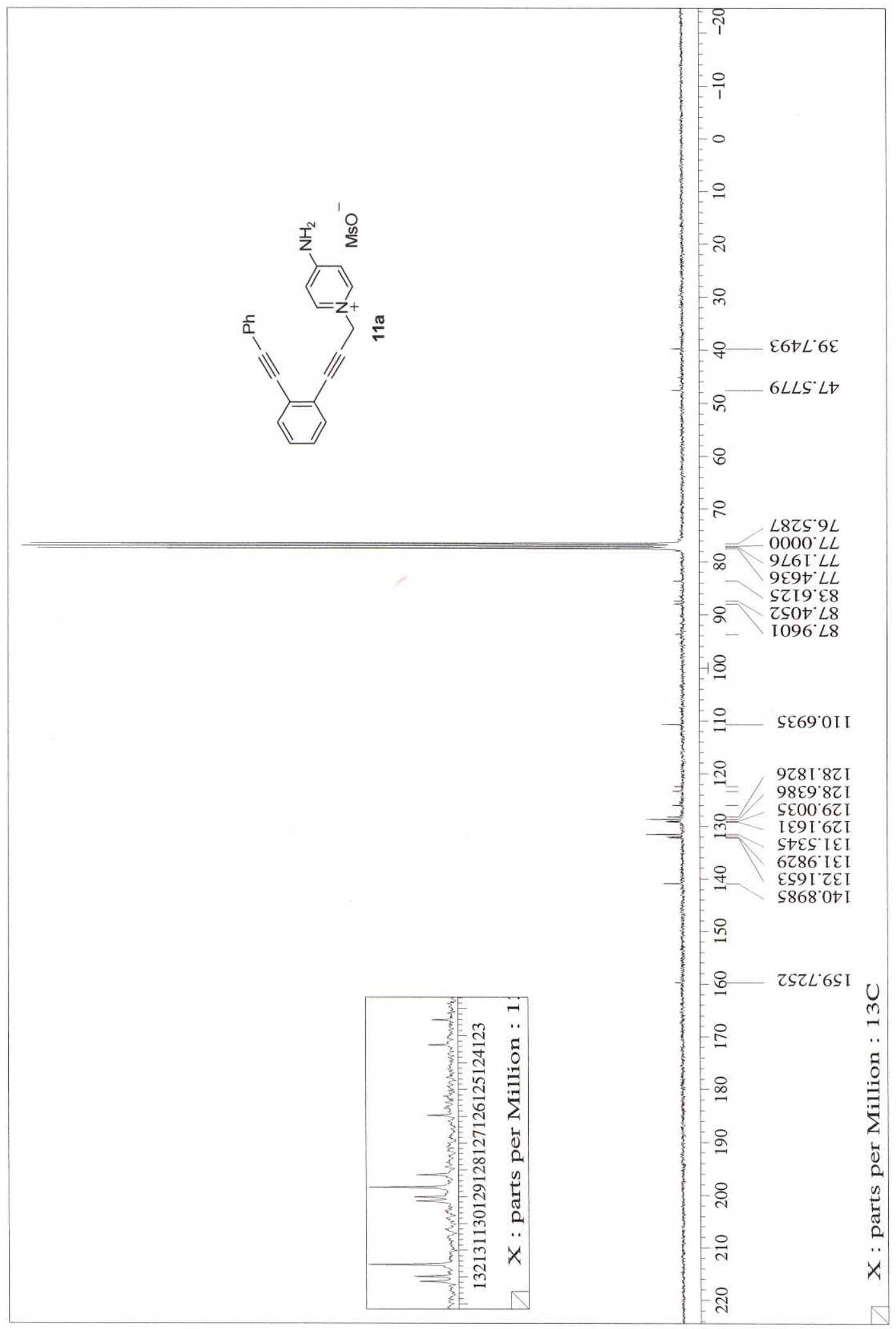




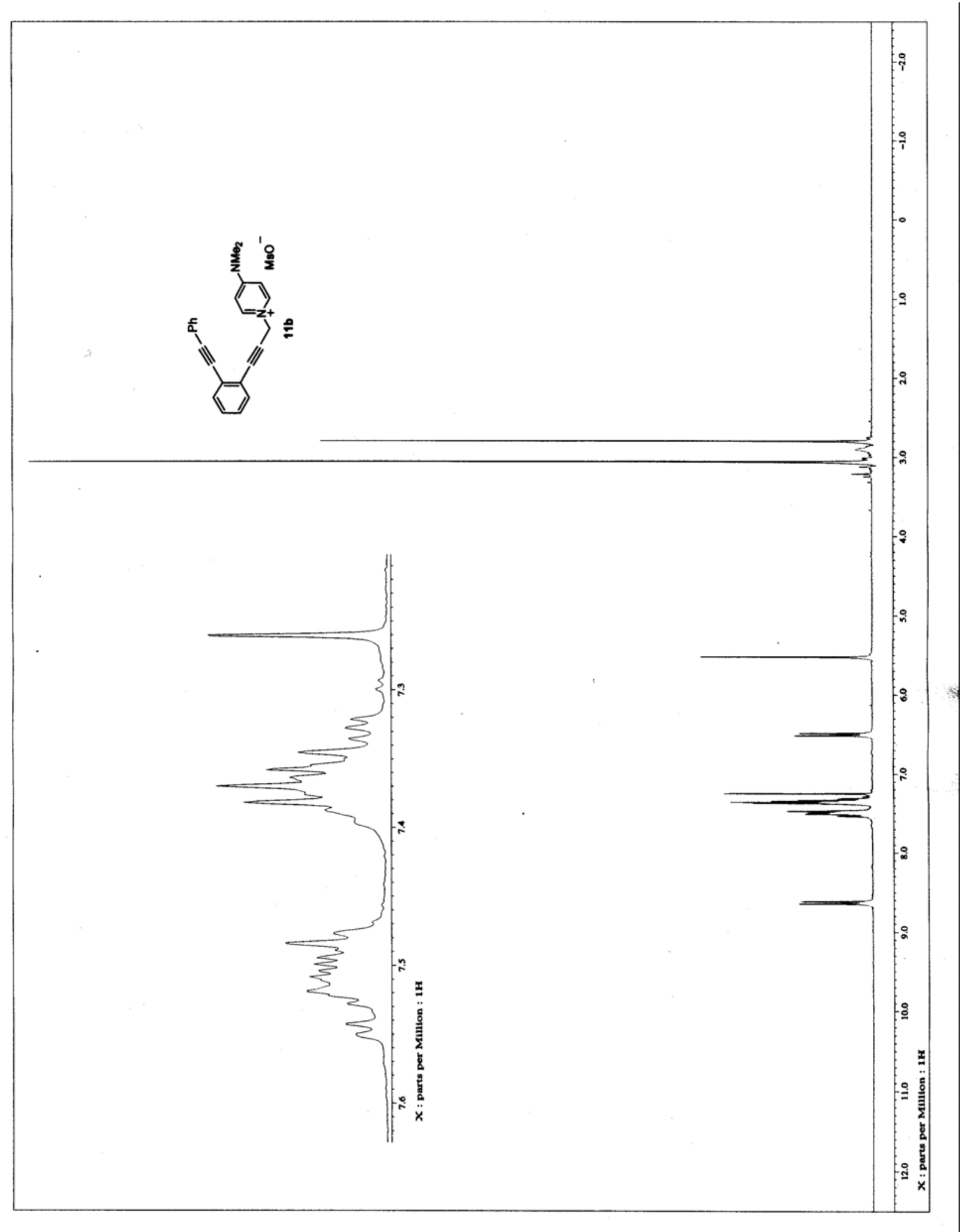




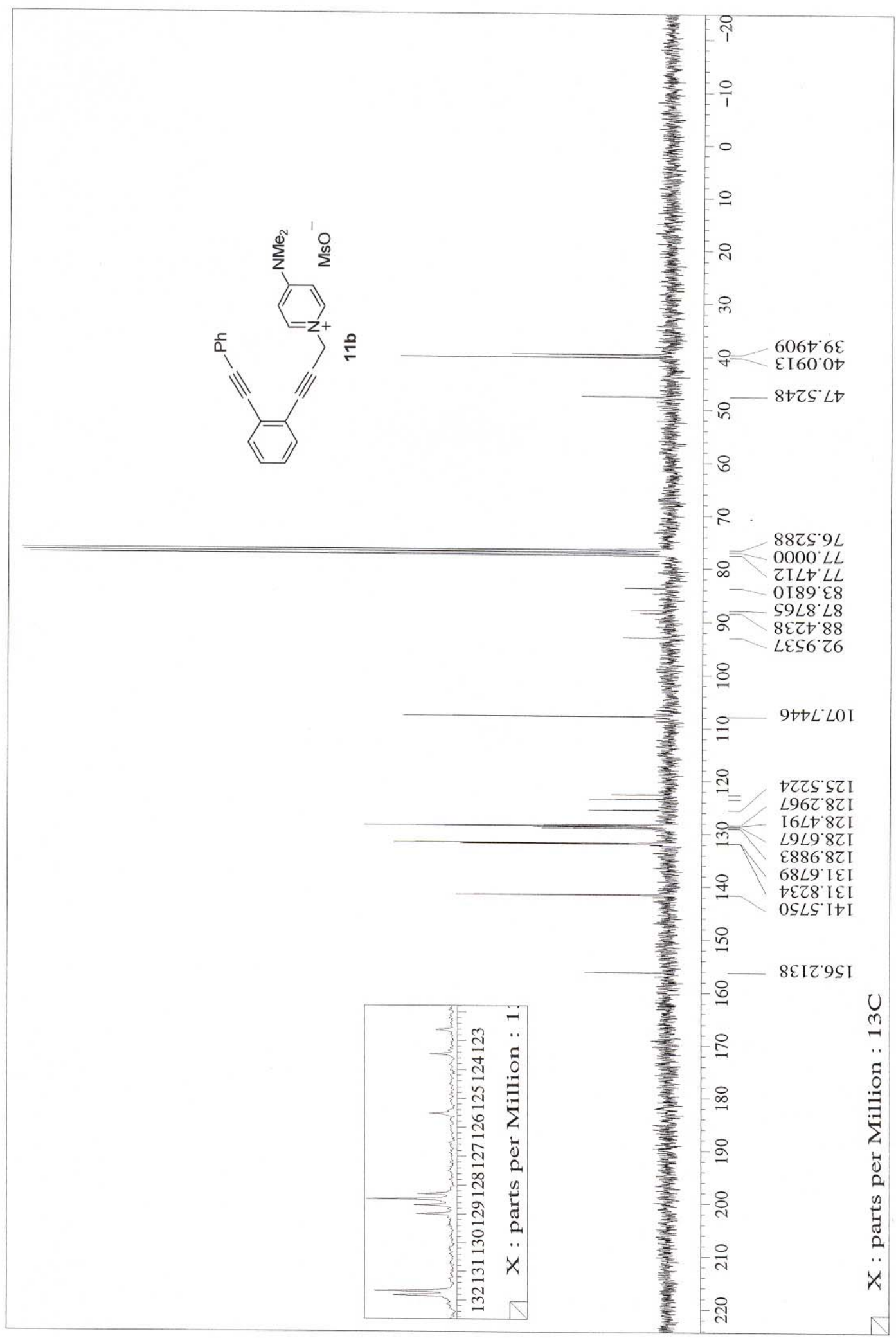




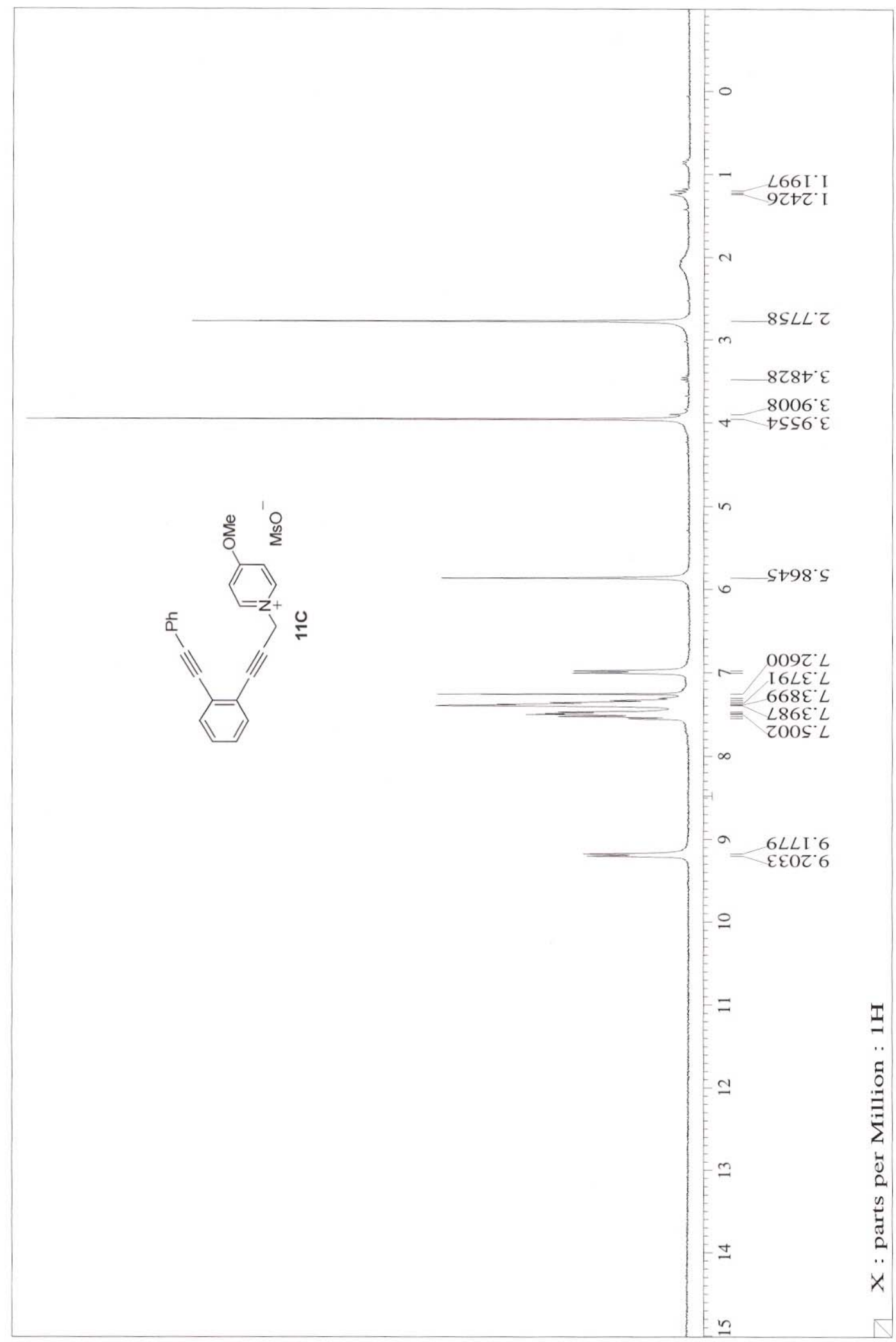




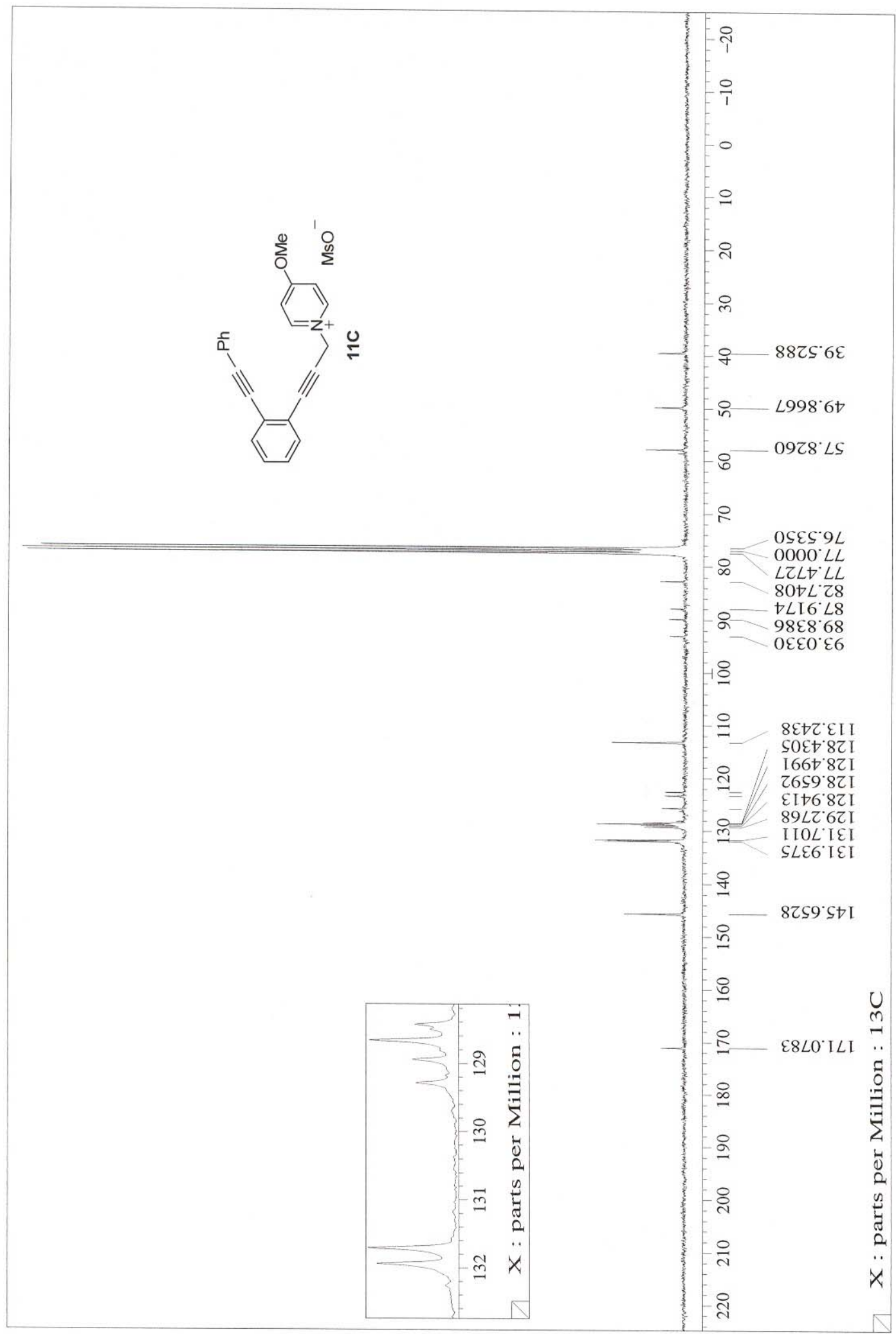




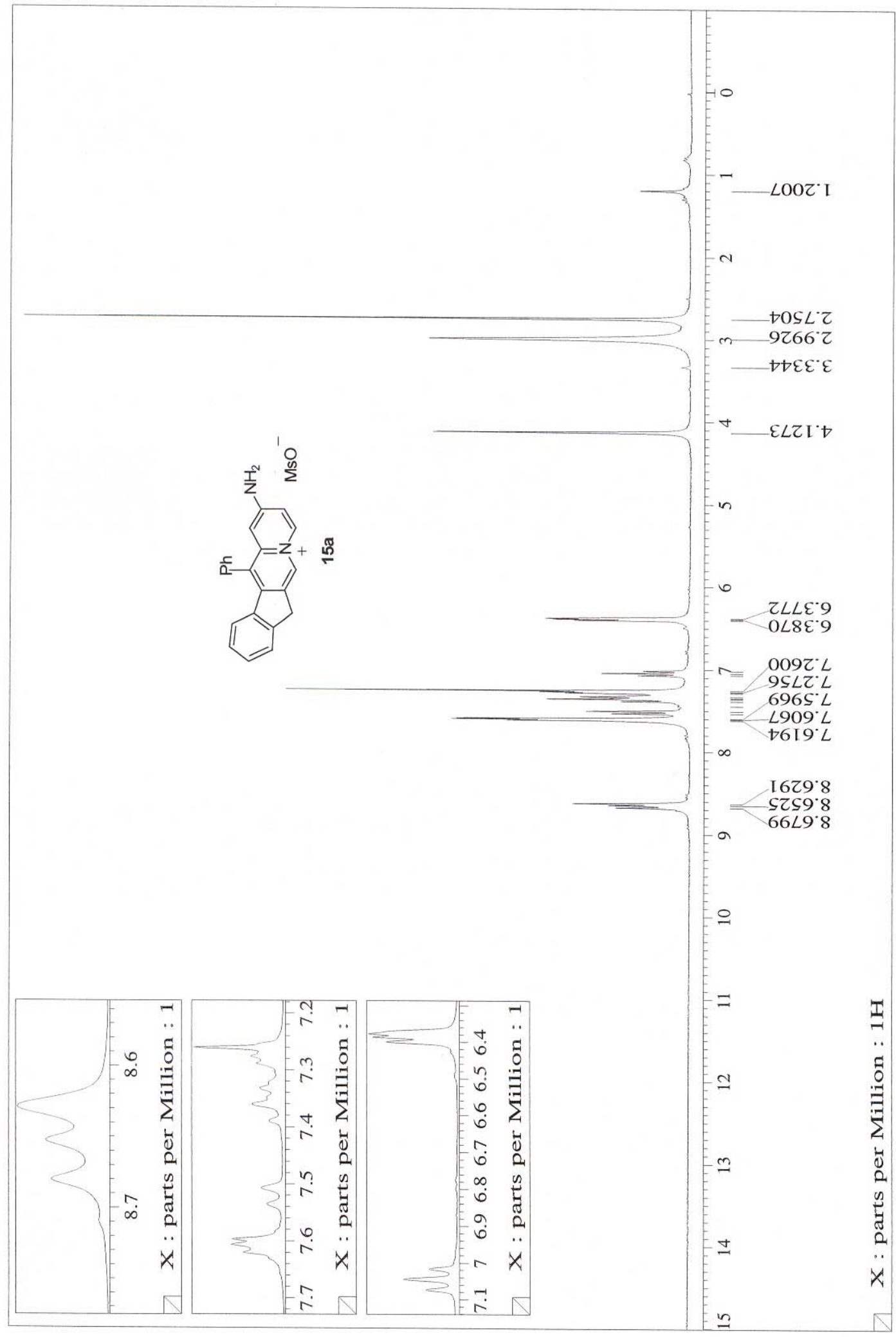




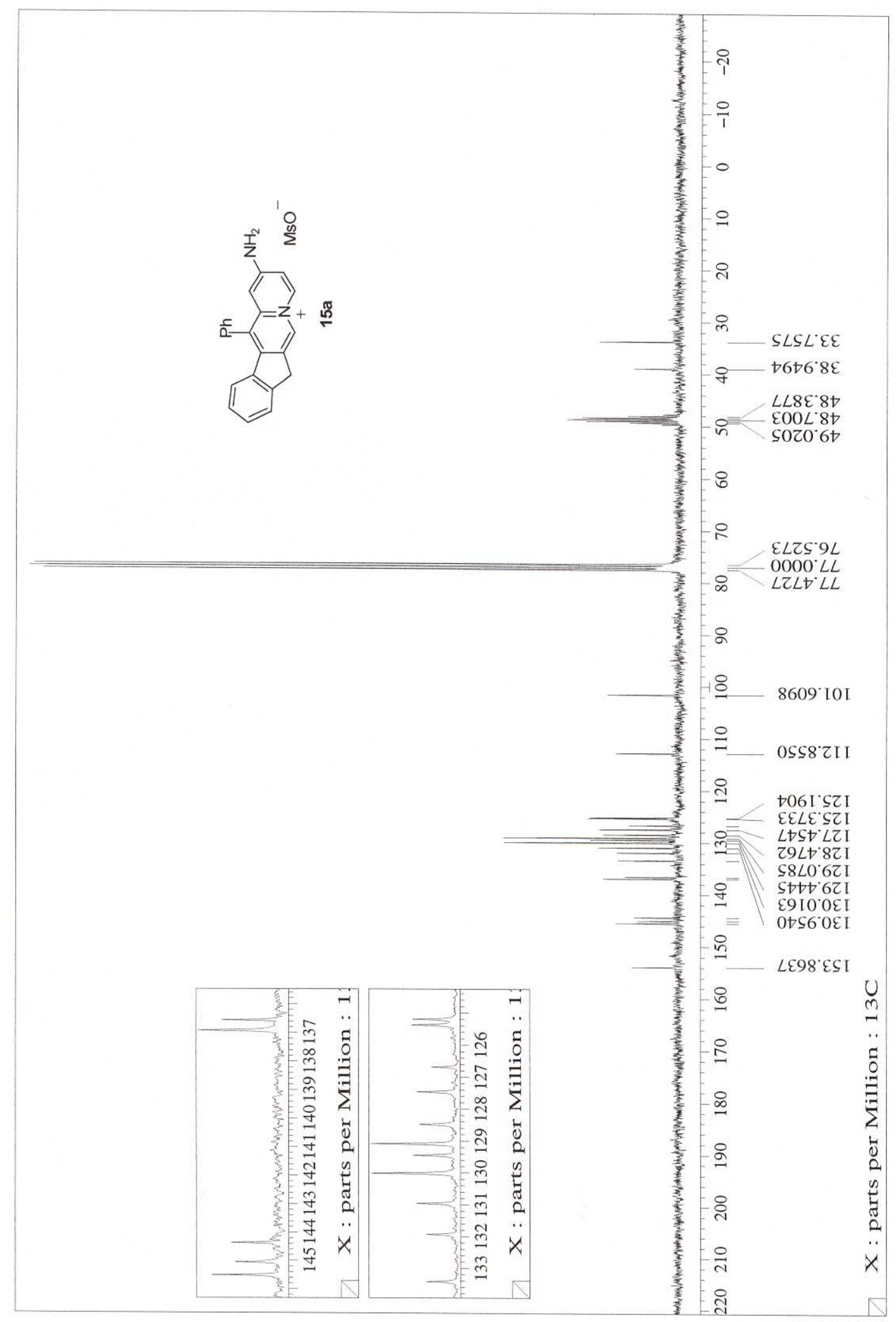




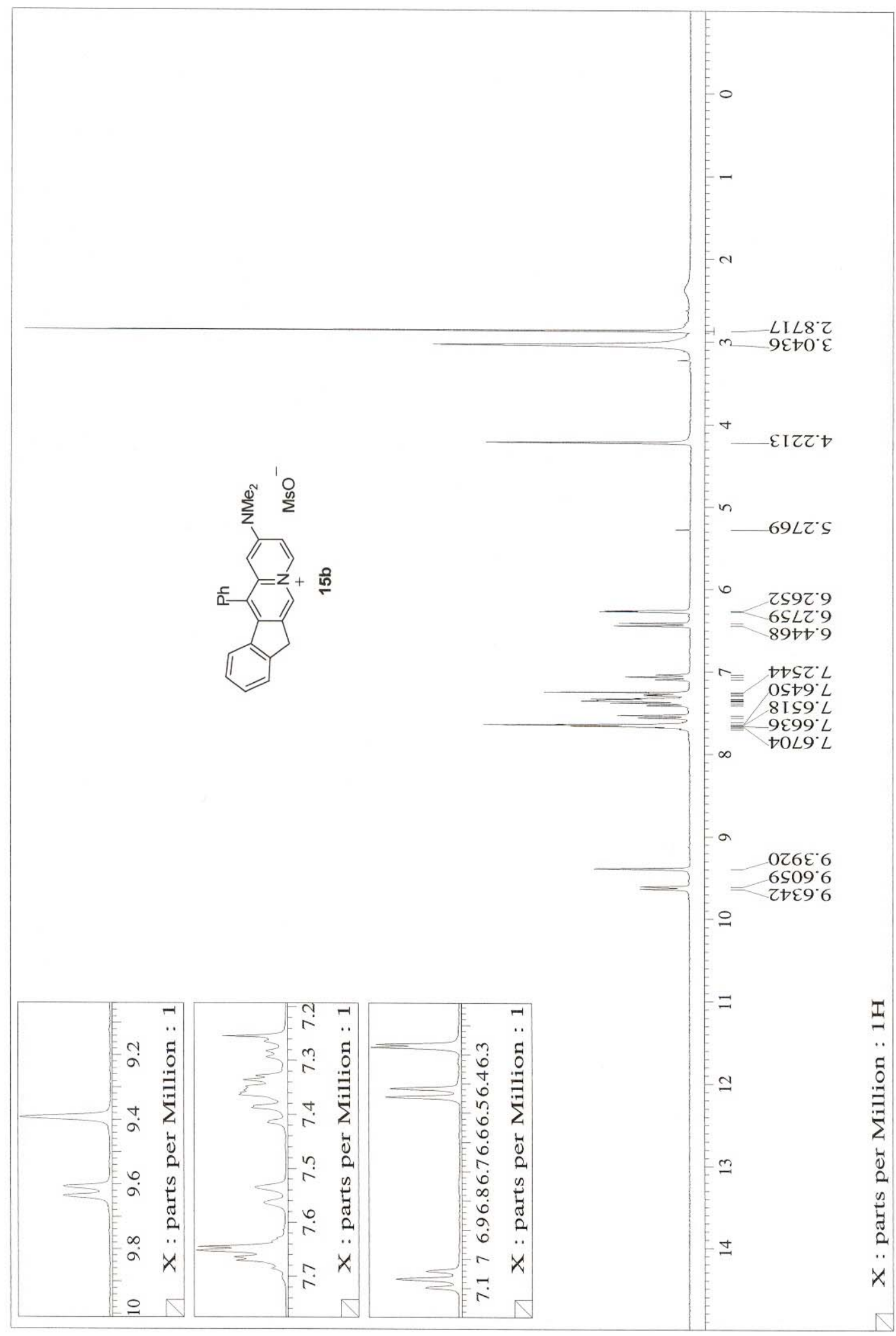




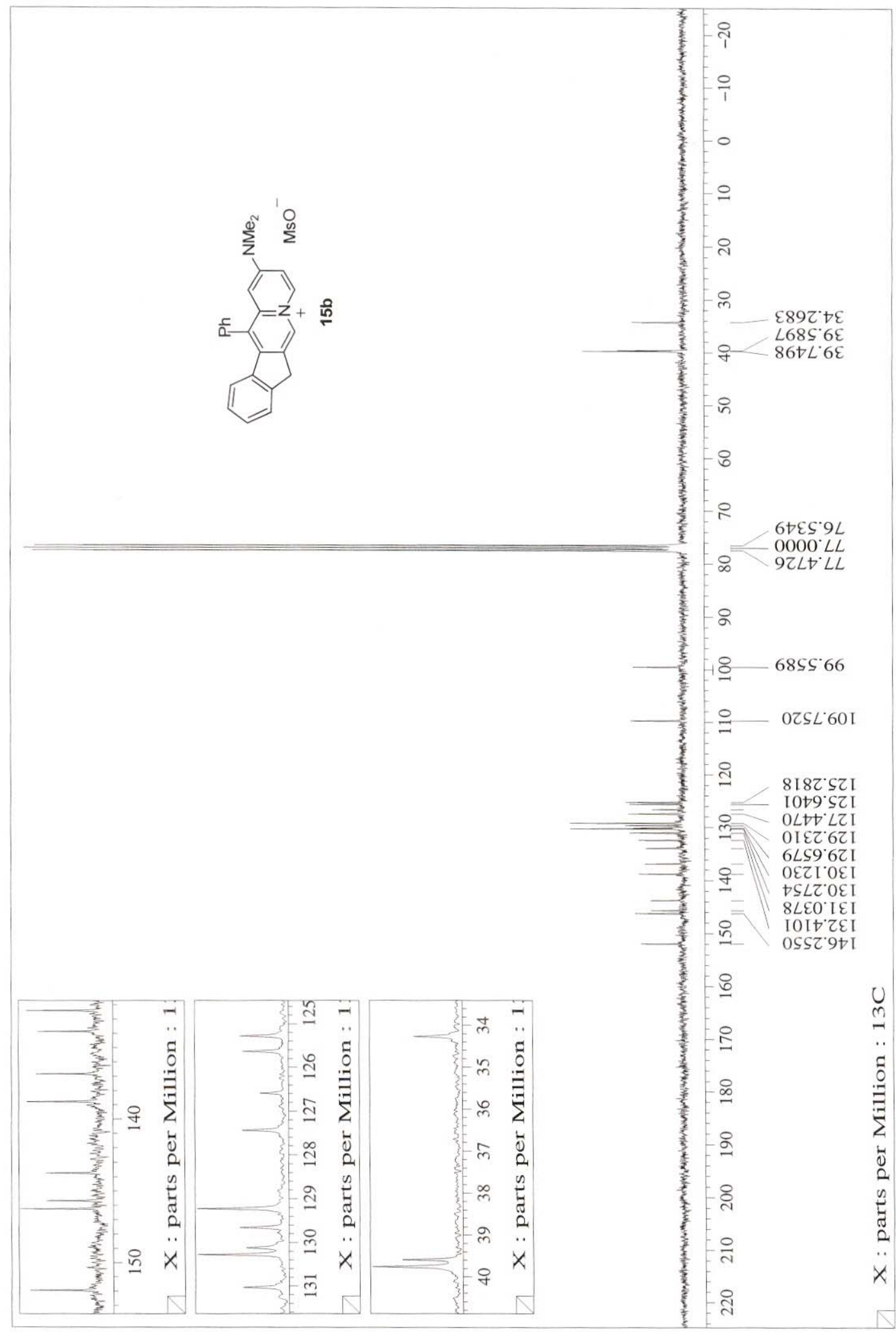




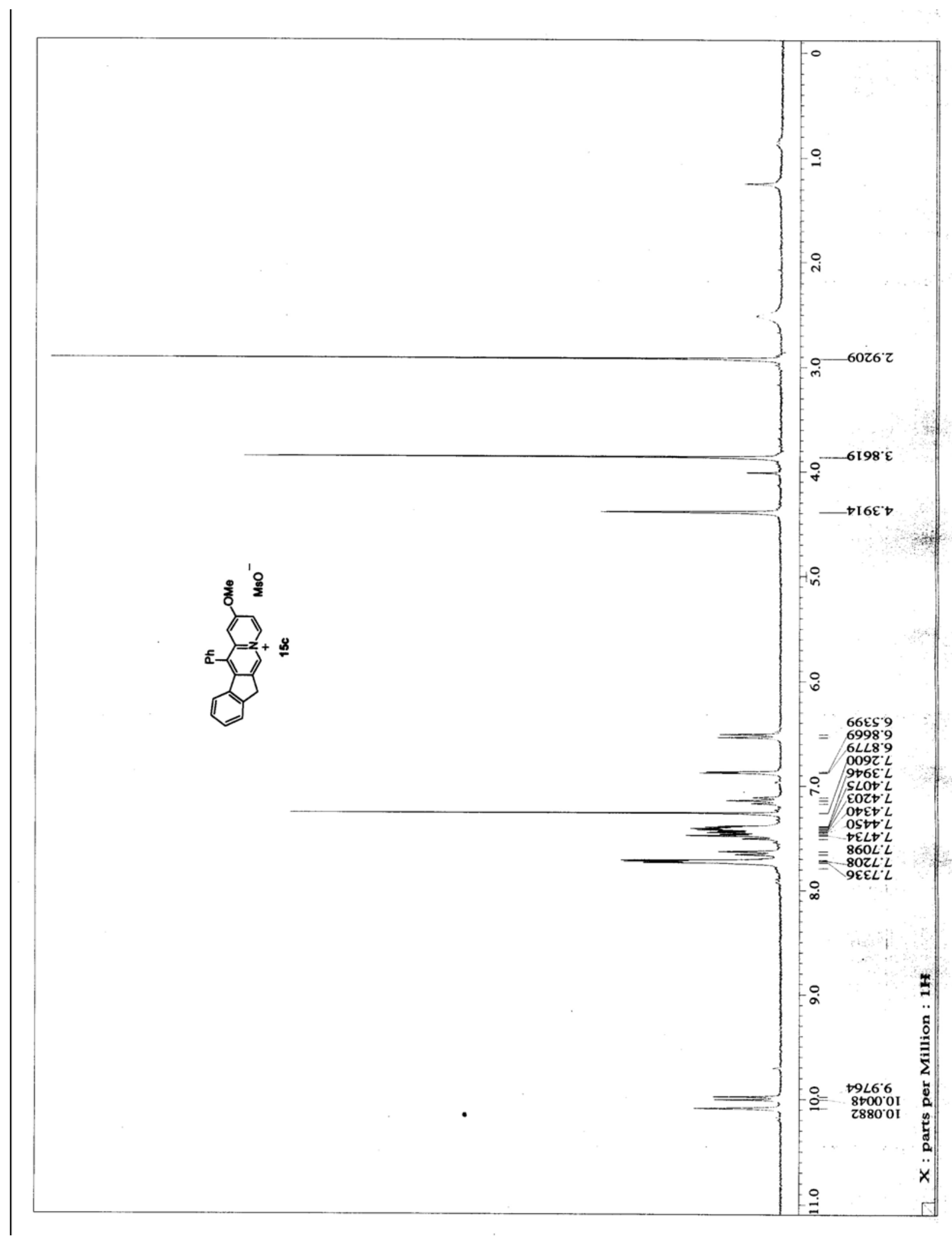




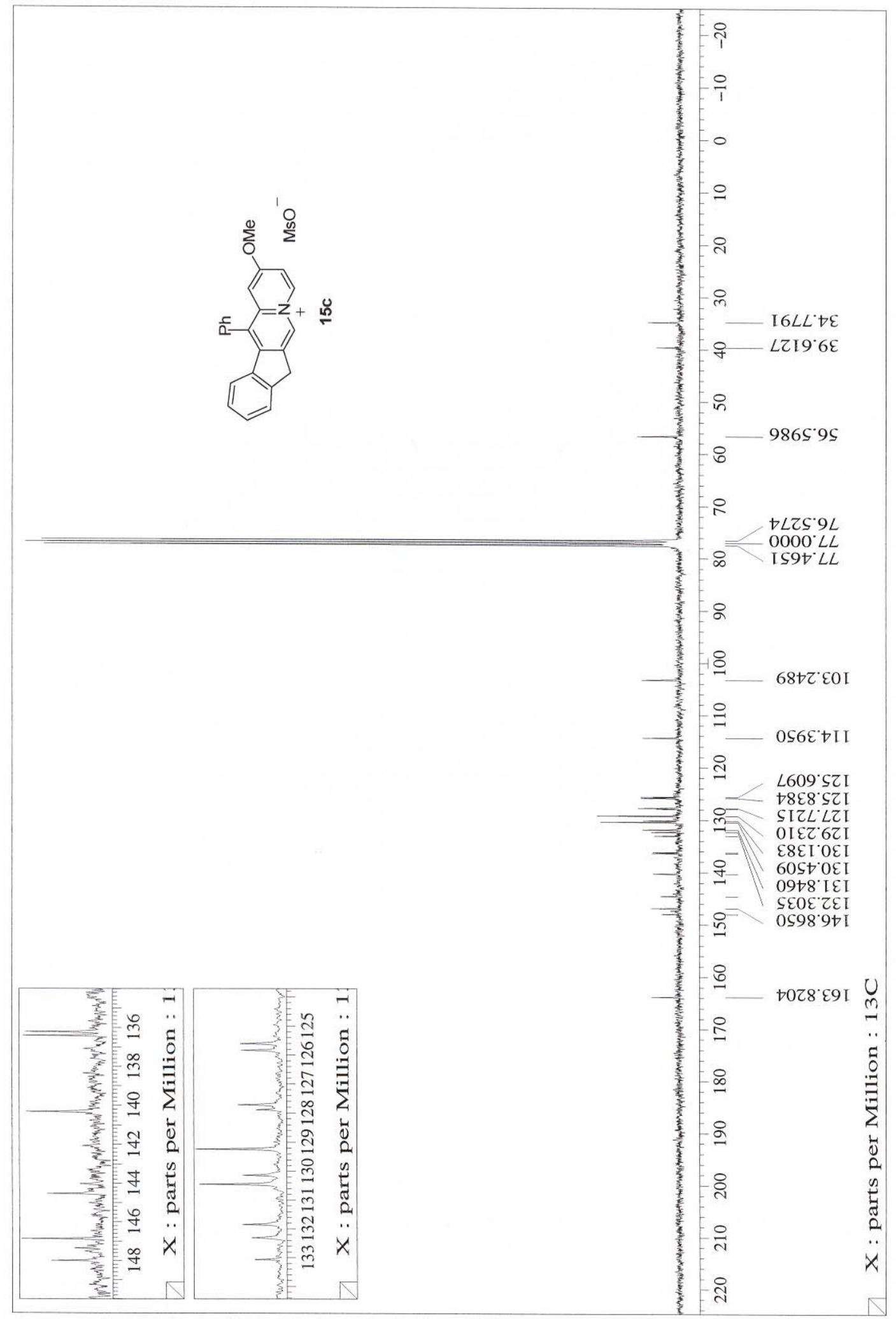




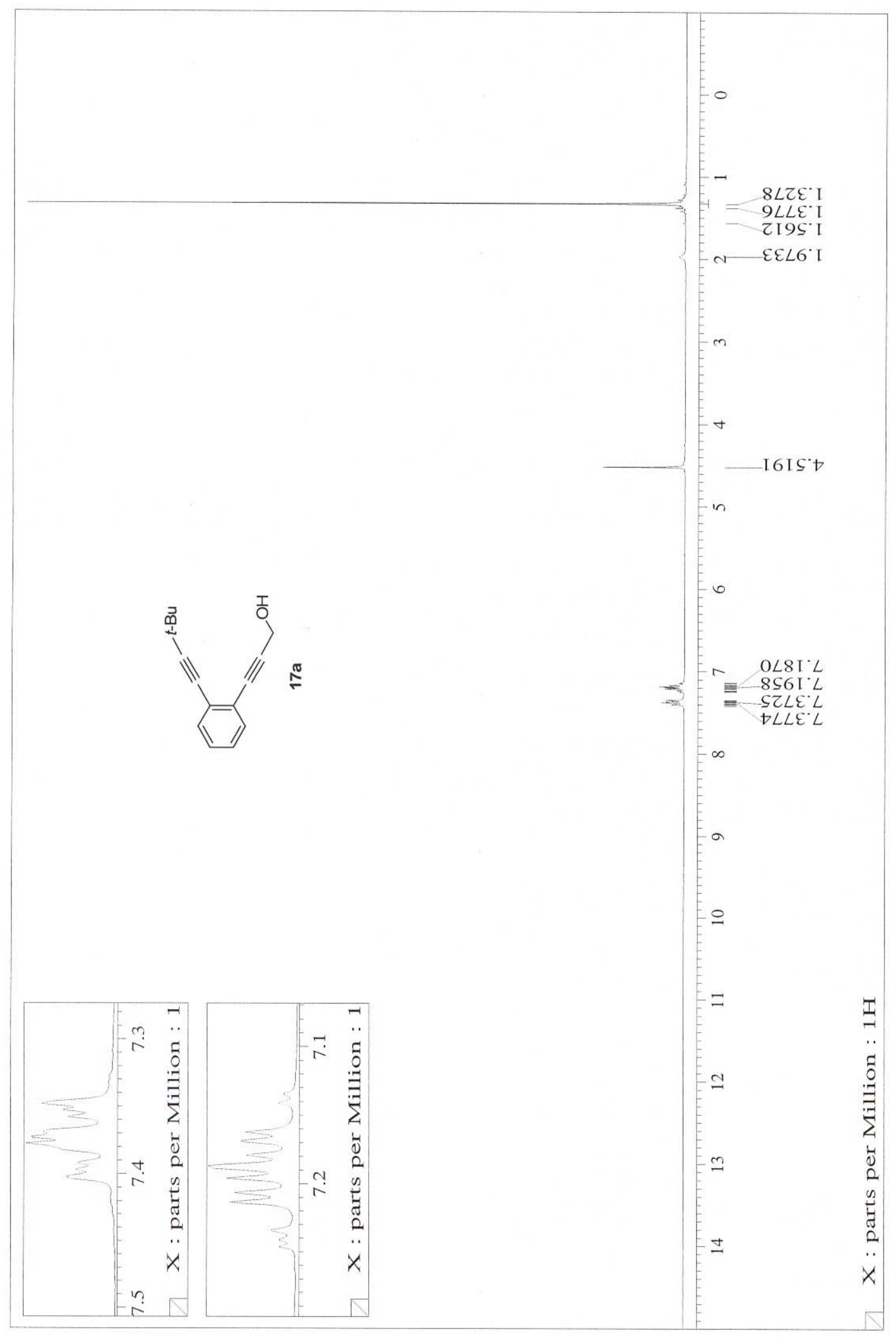

S25 


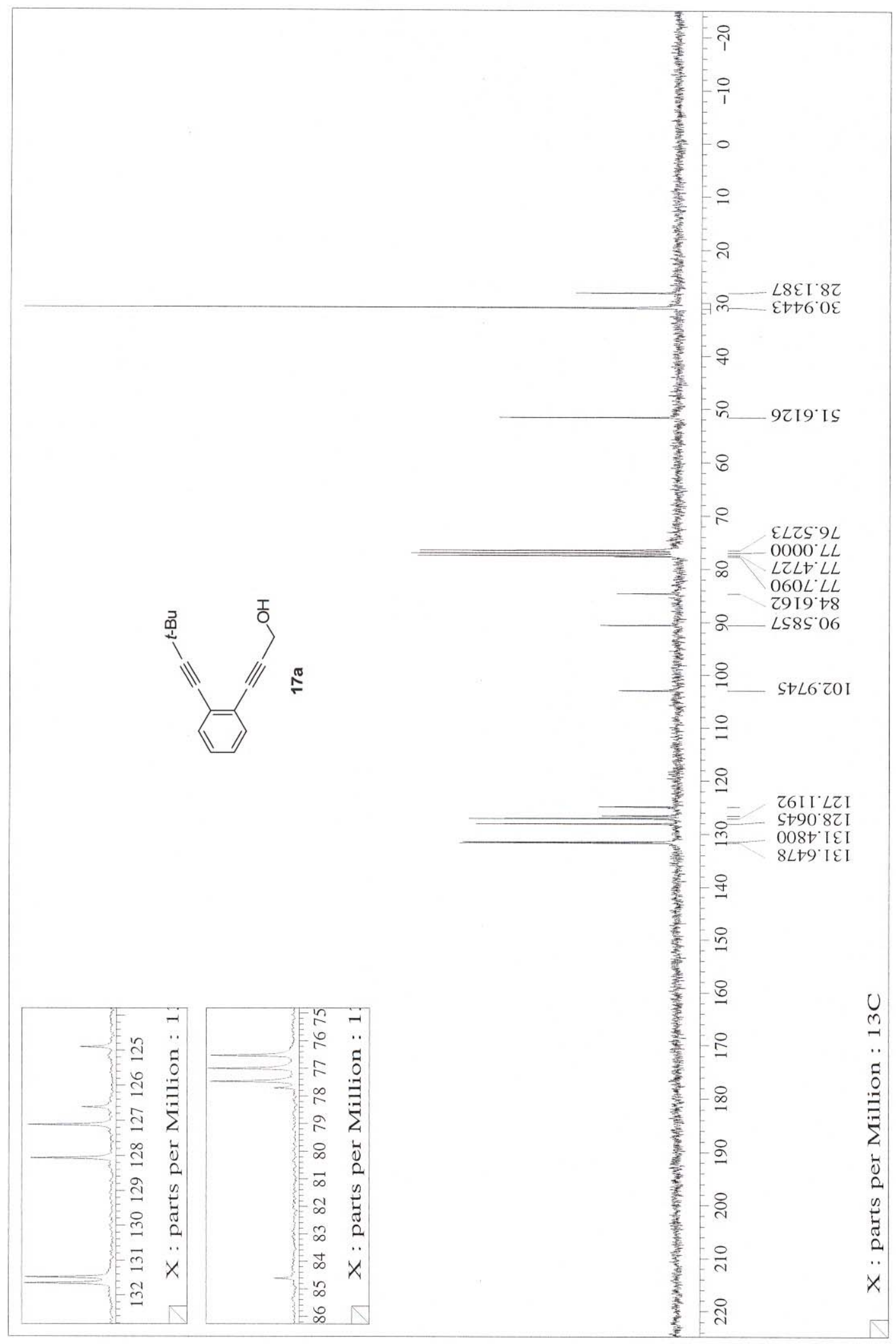




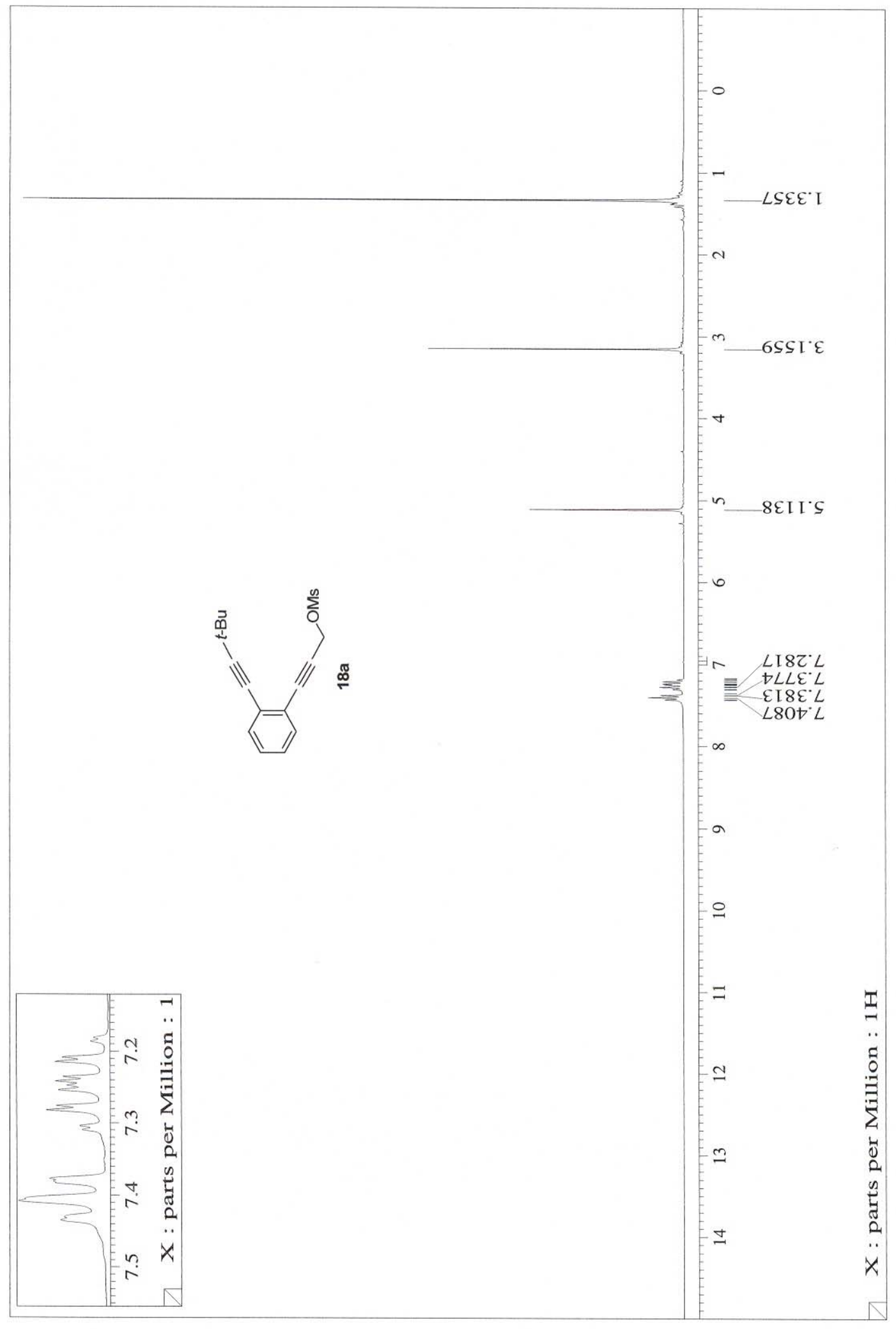




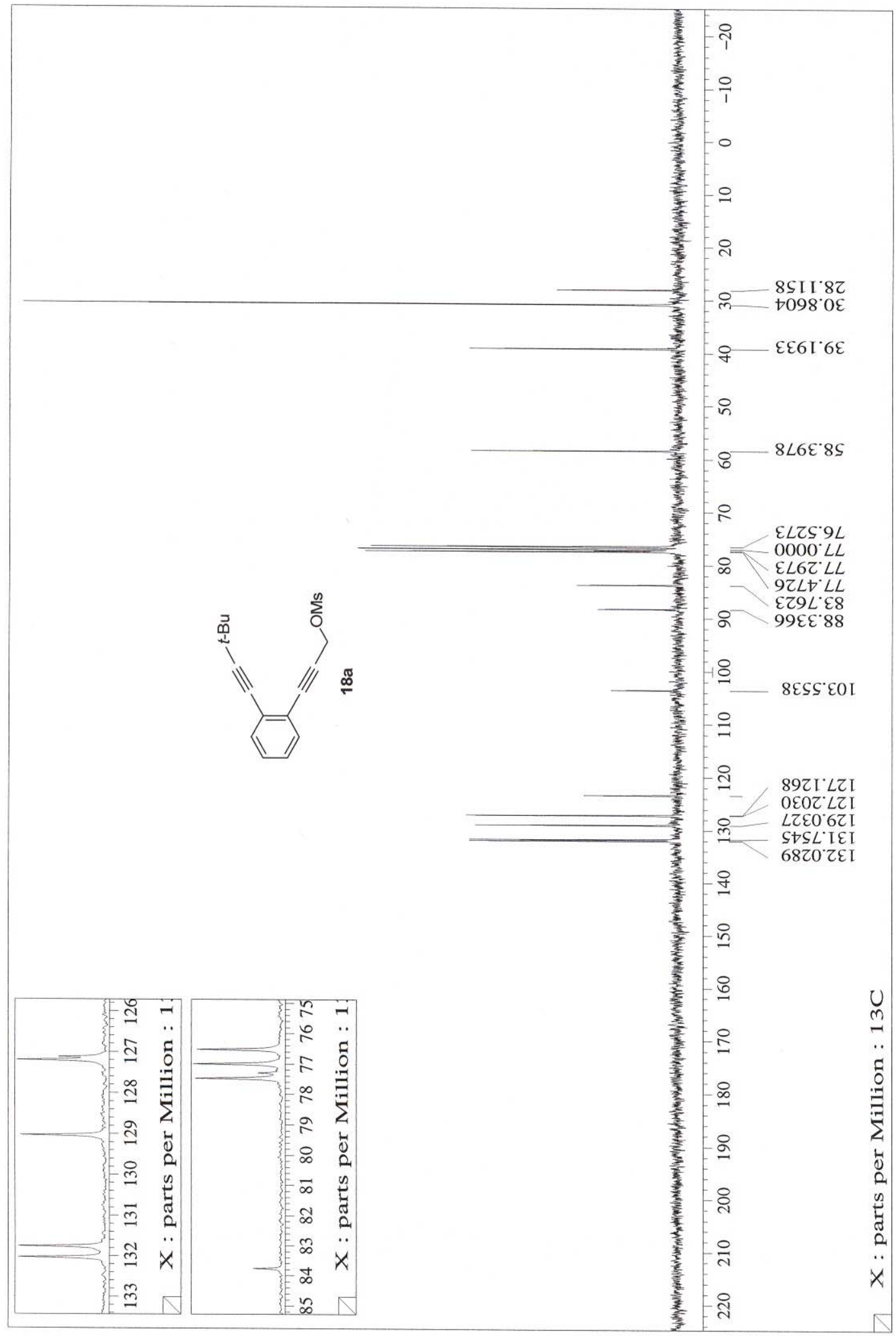




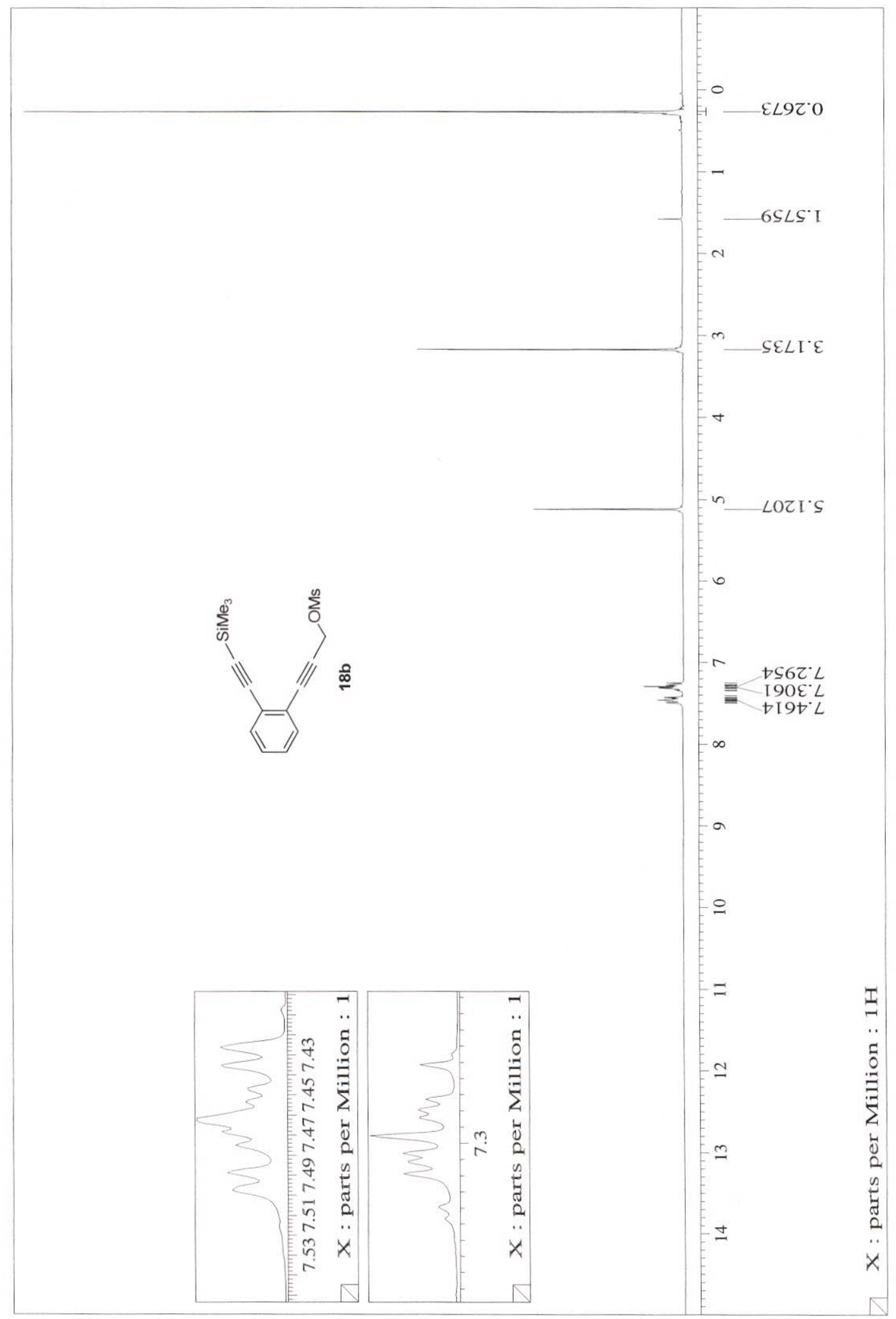




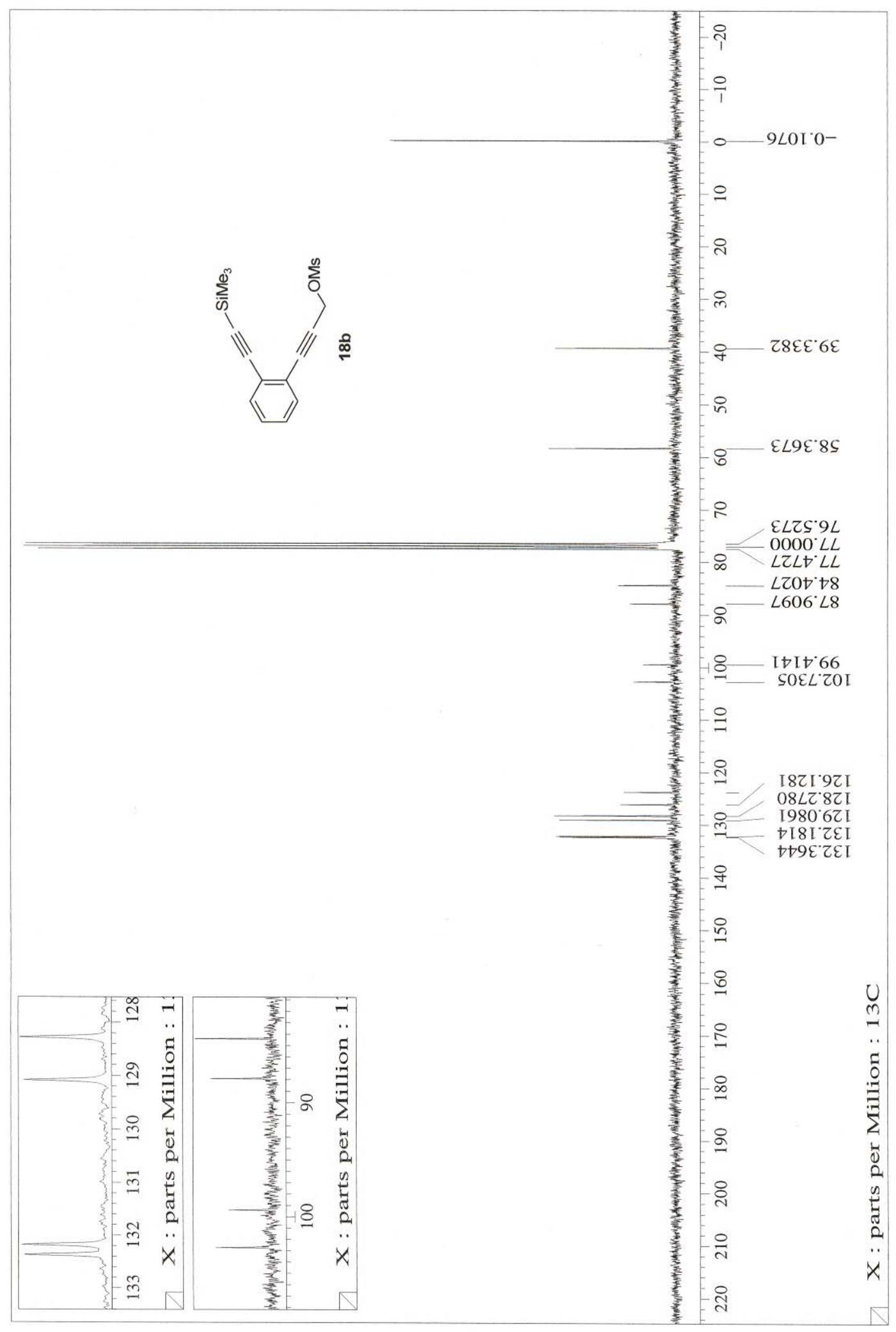




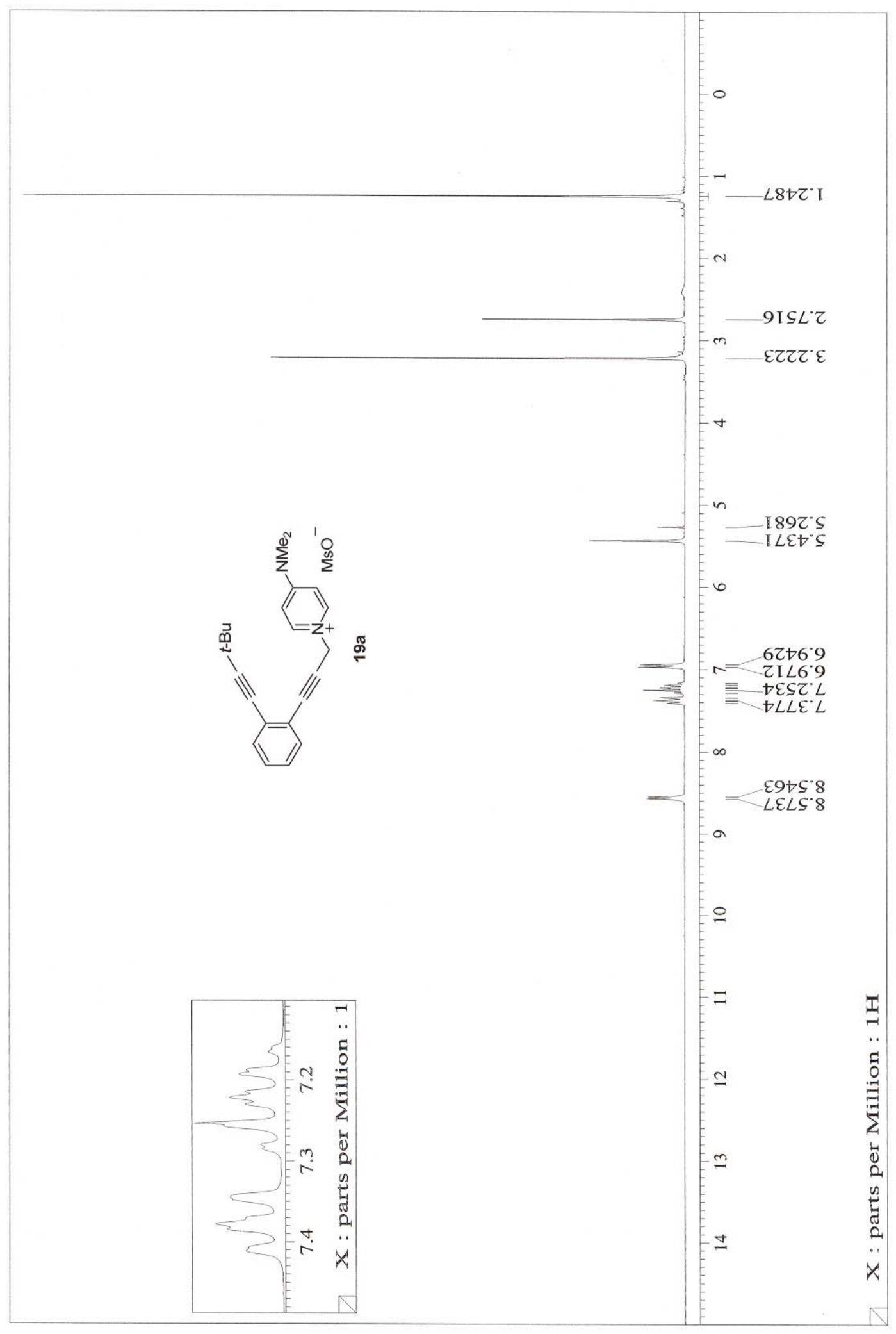




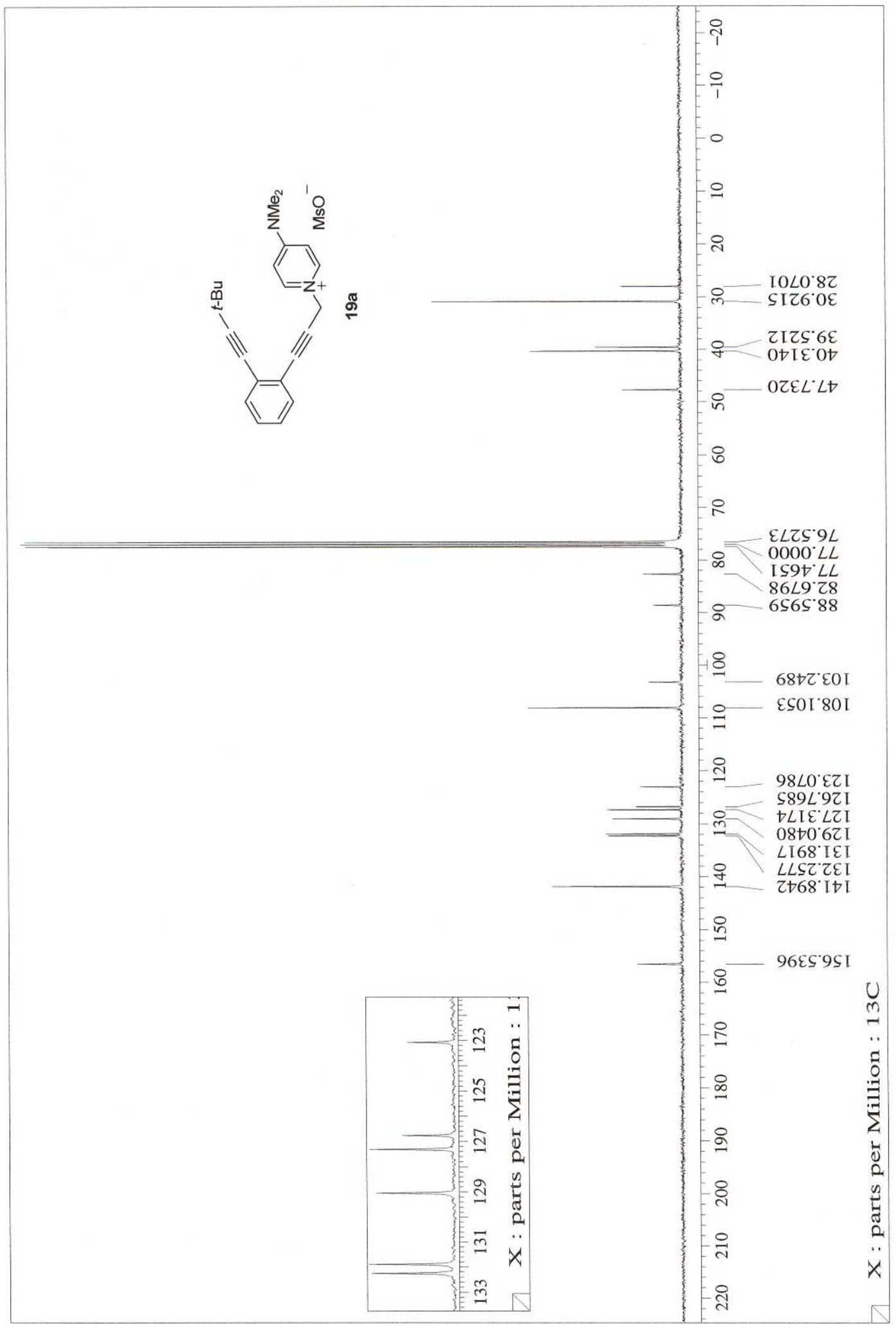




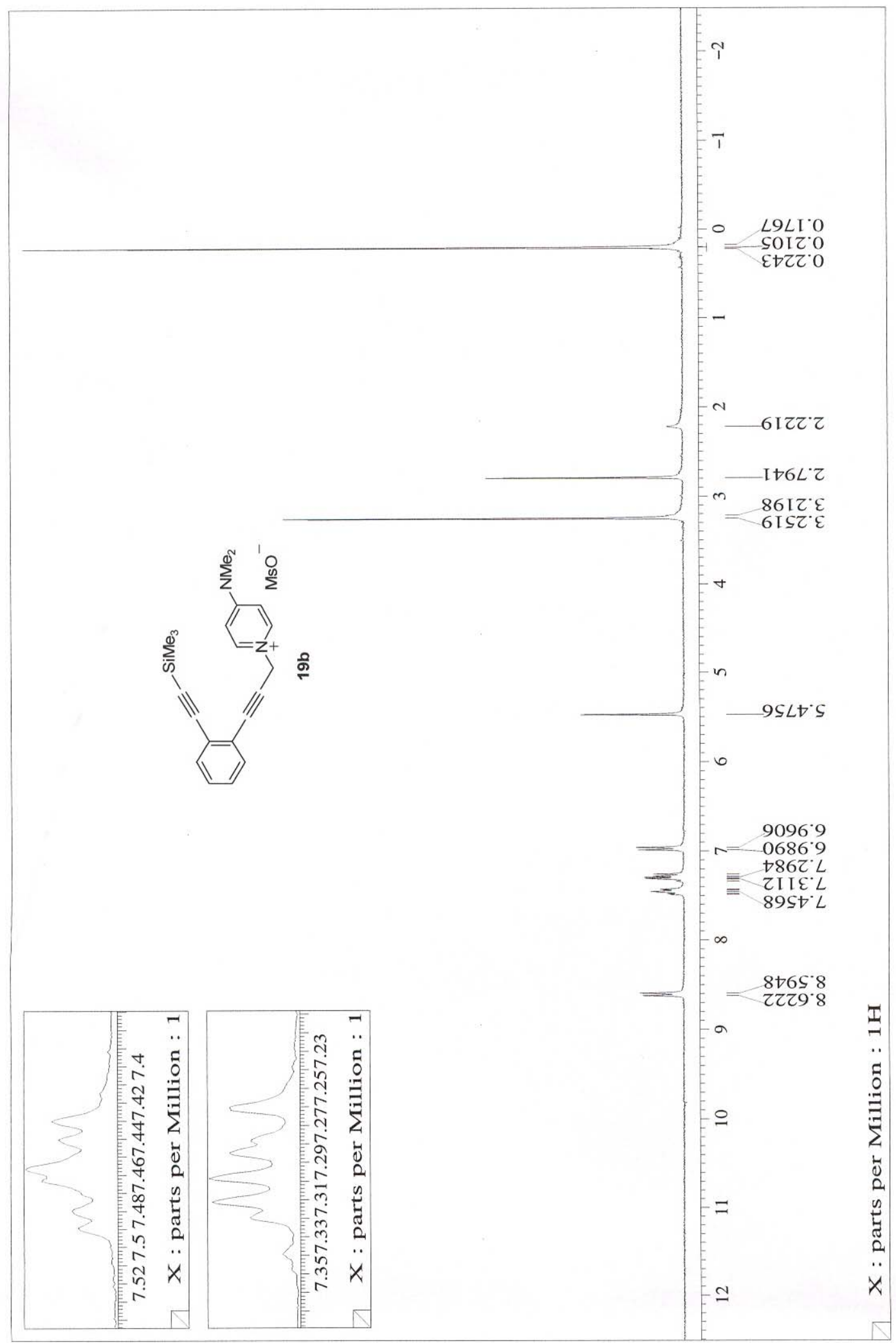




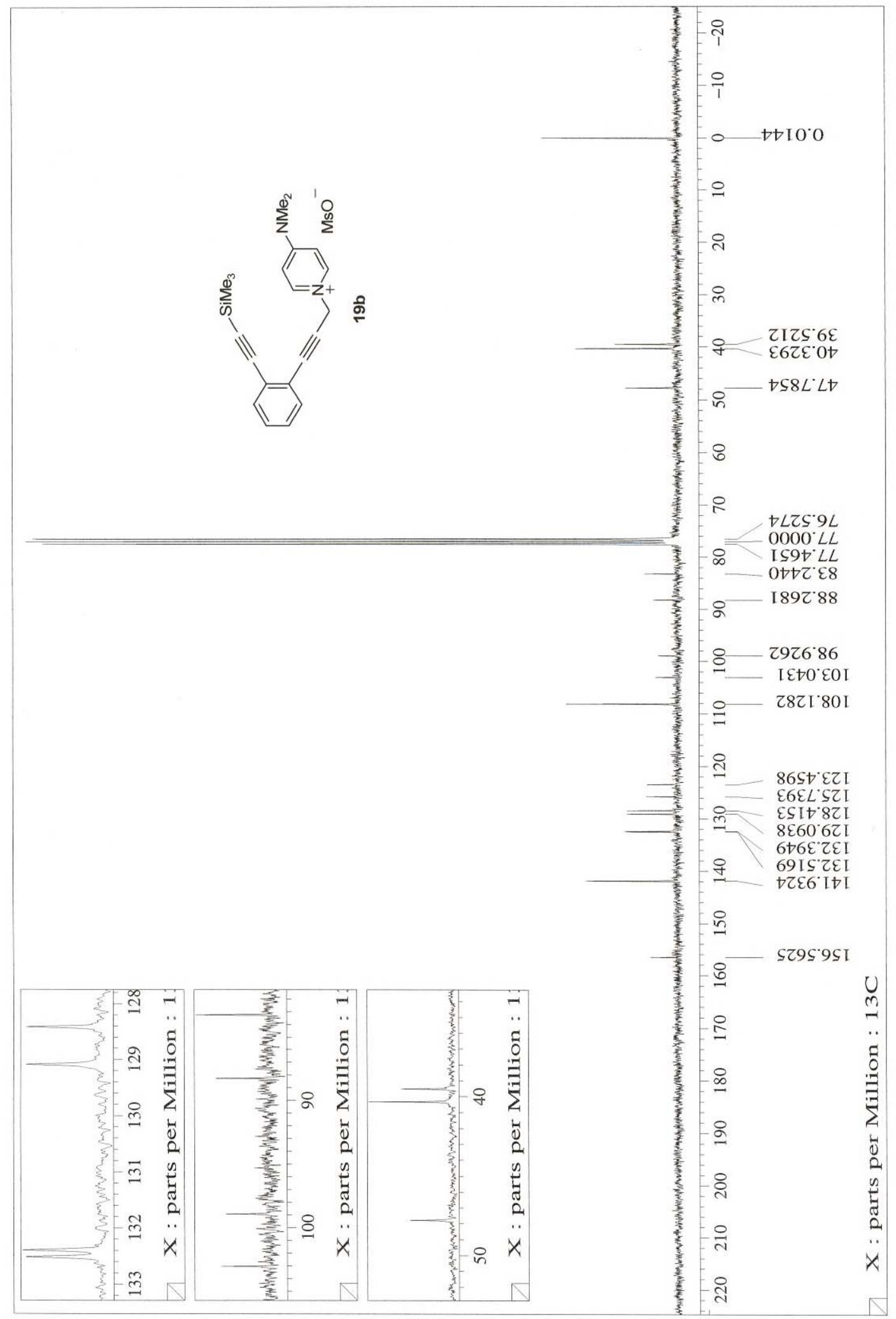




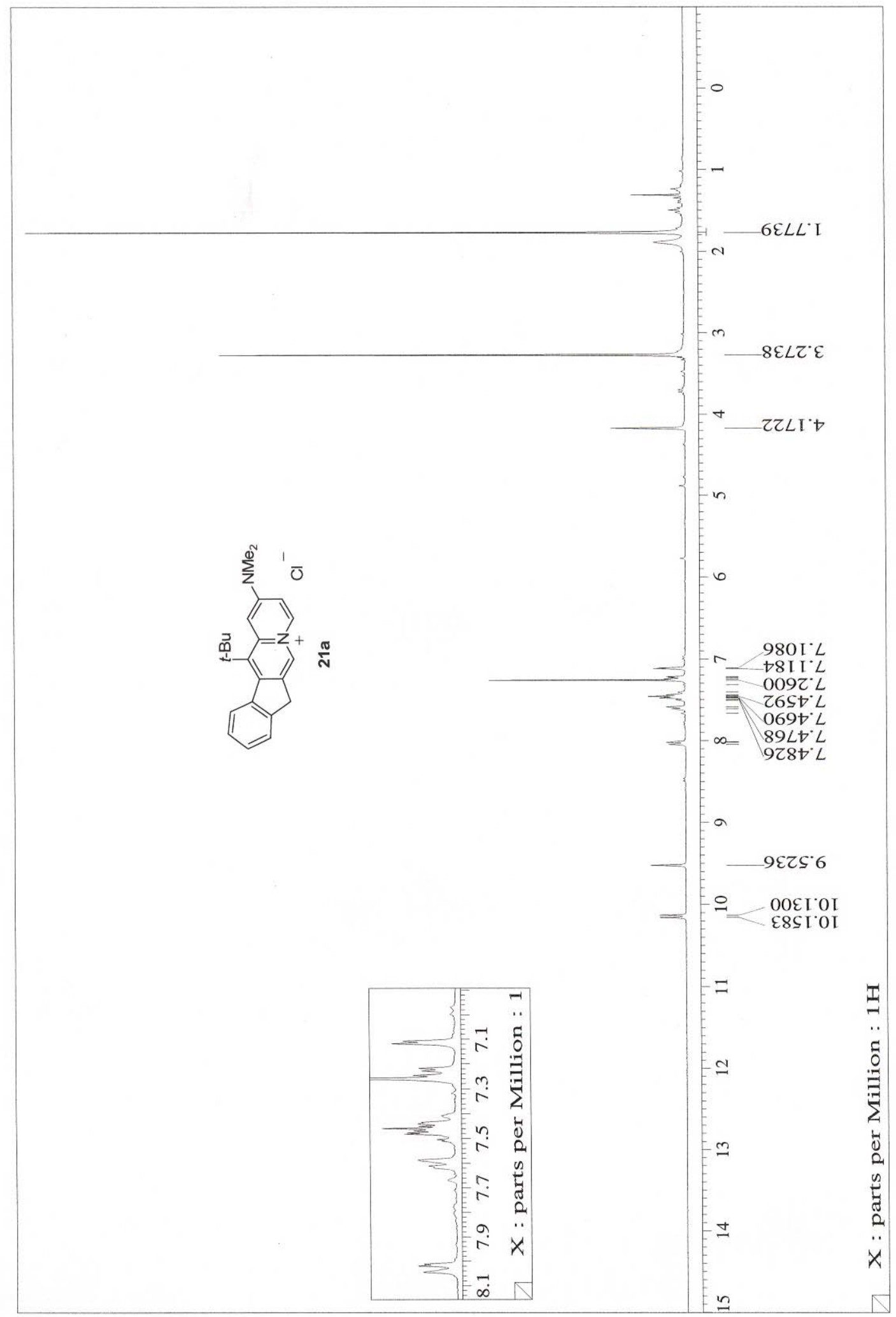




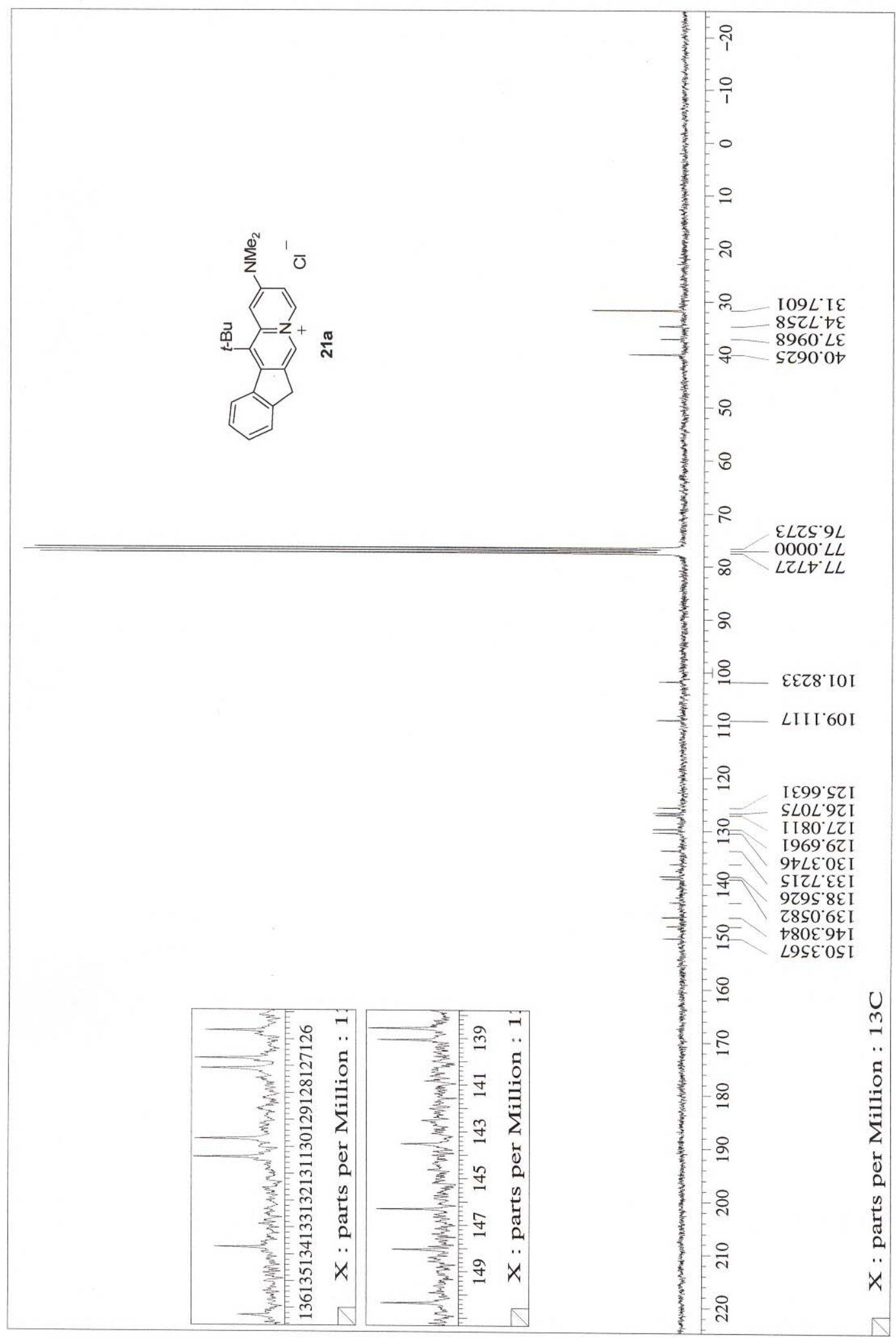




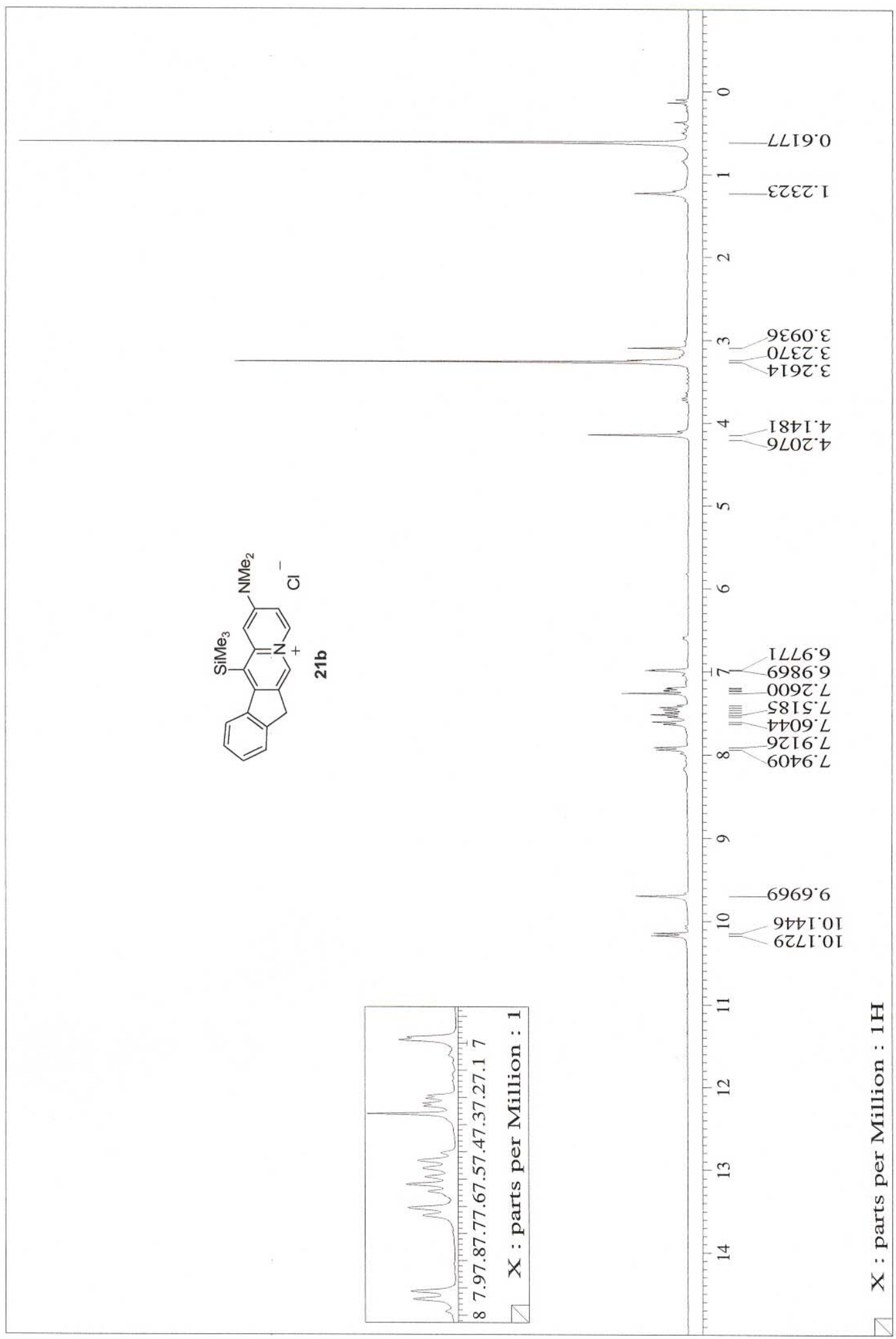




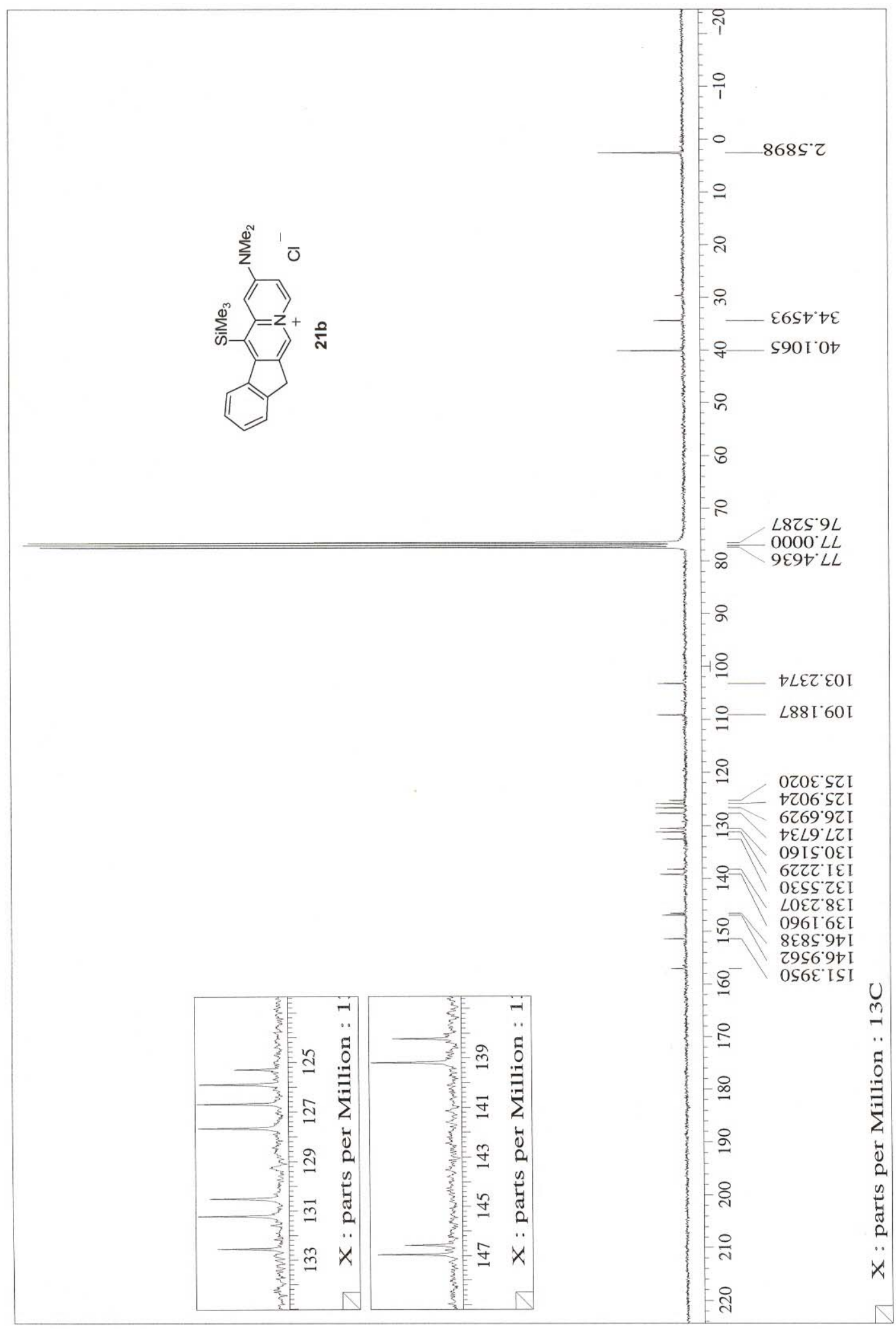




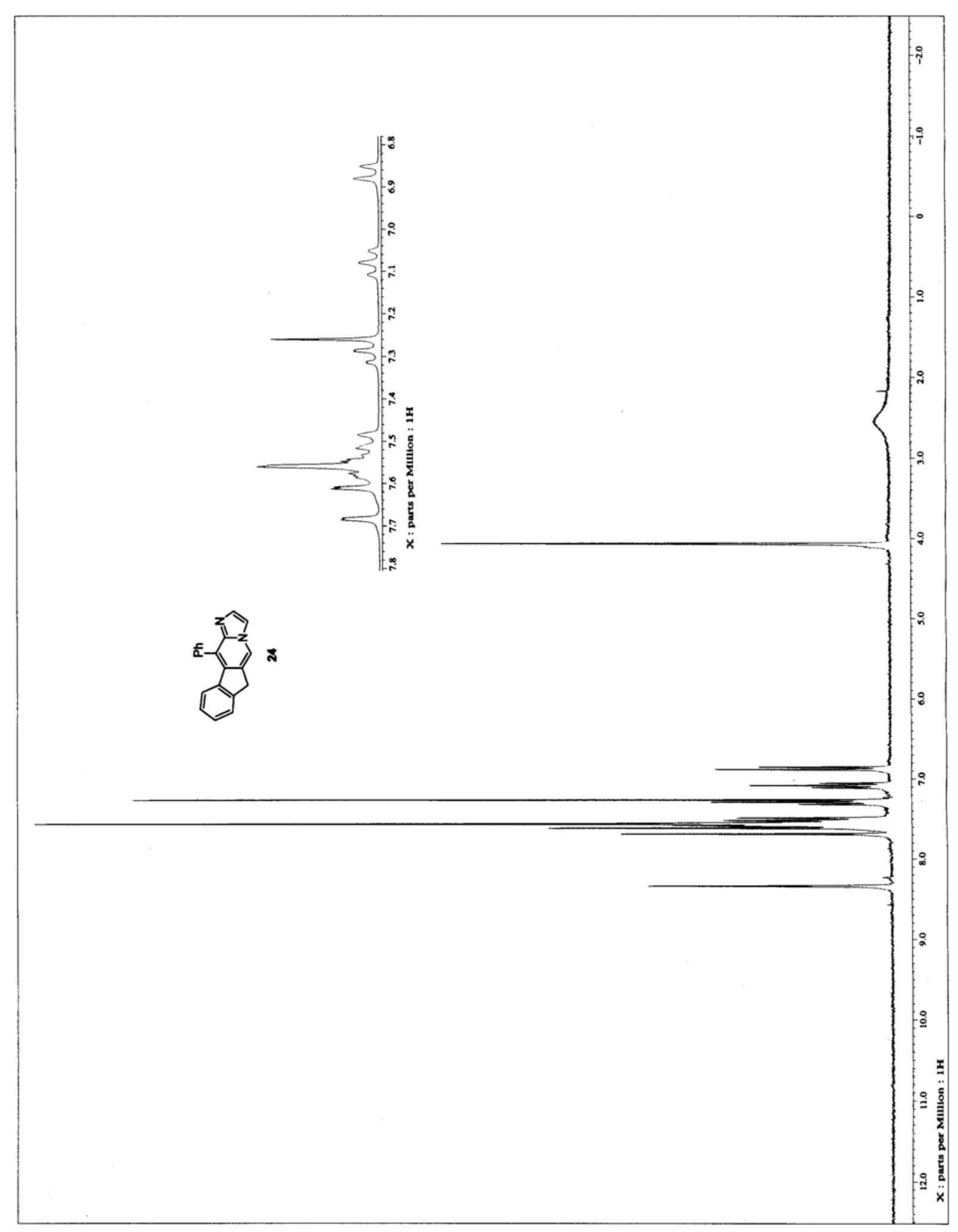




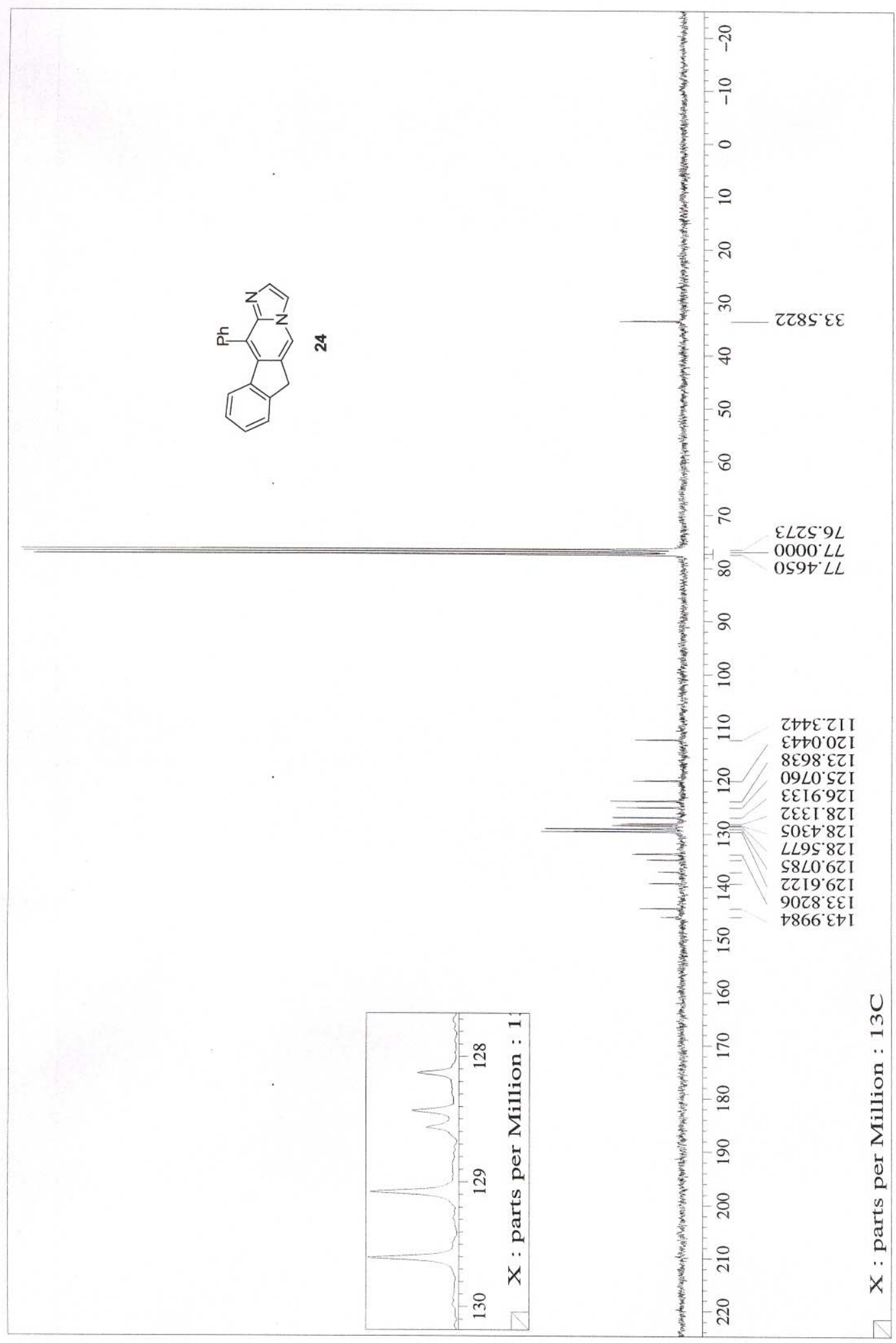




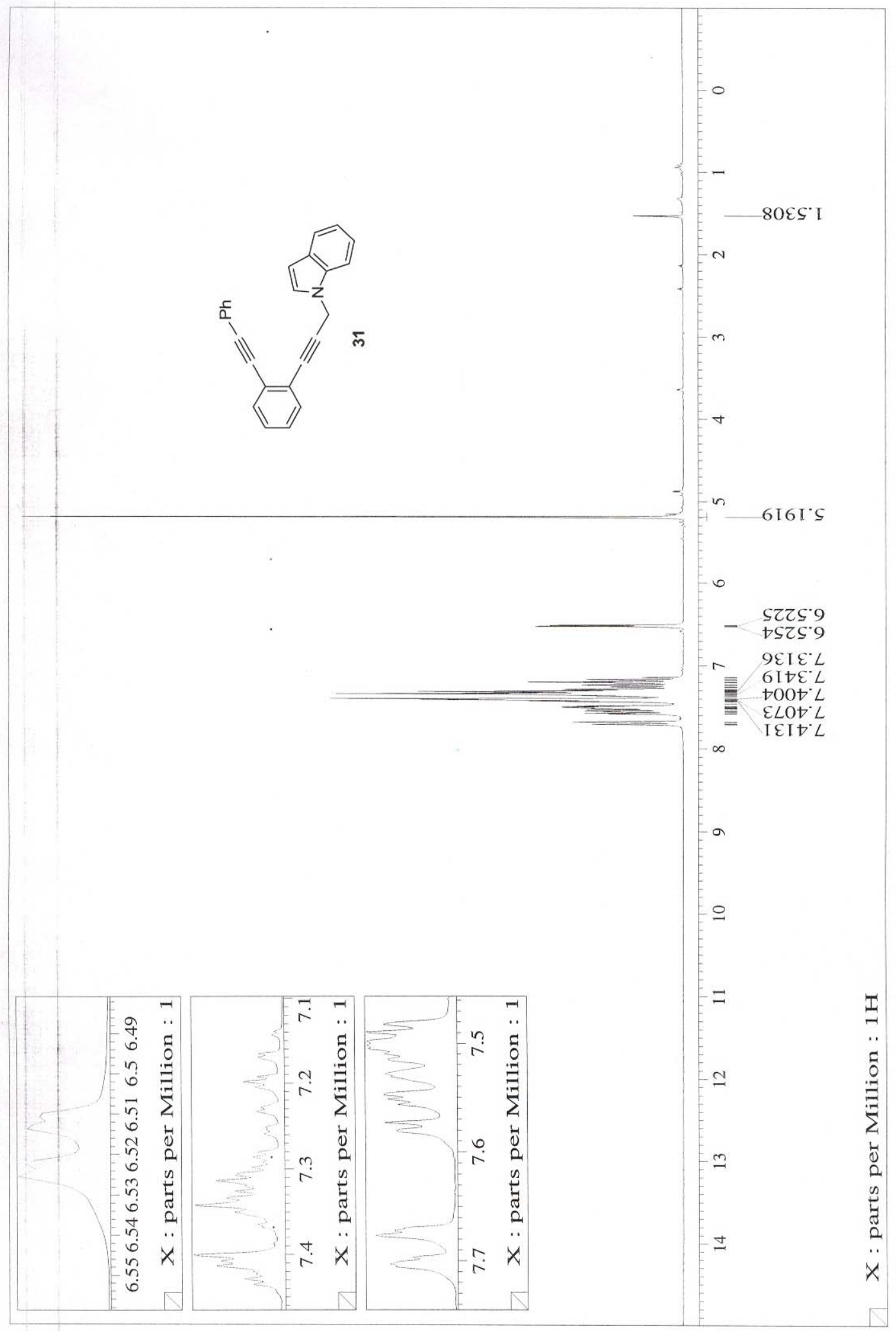




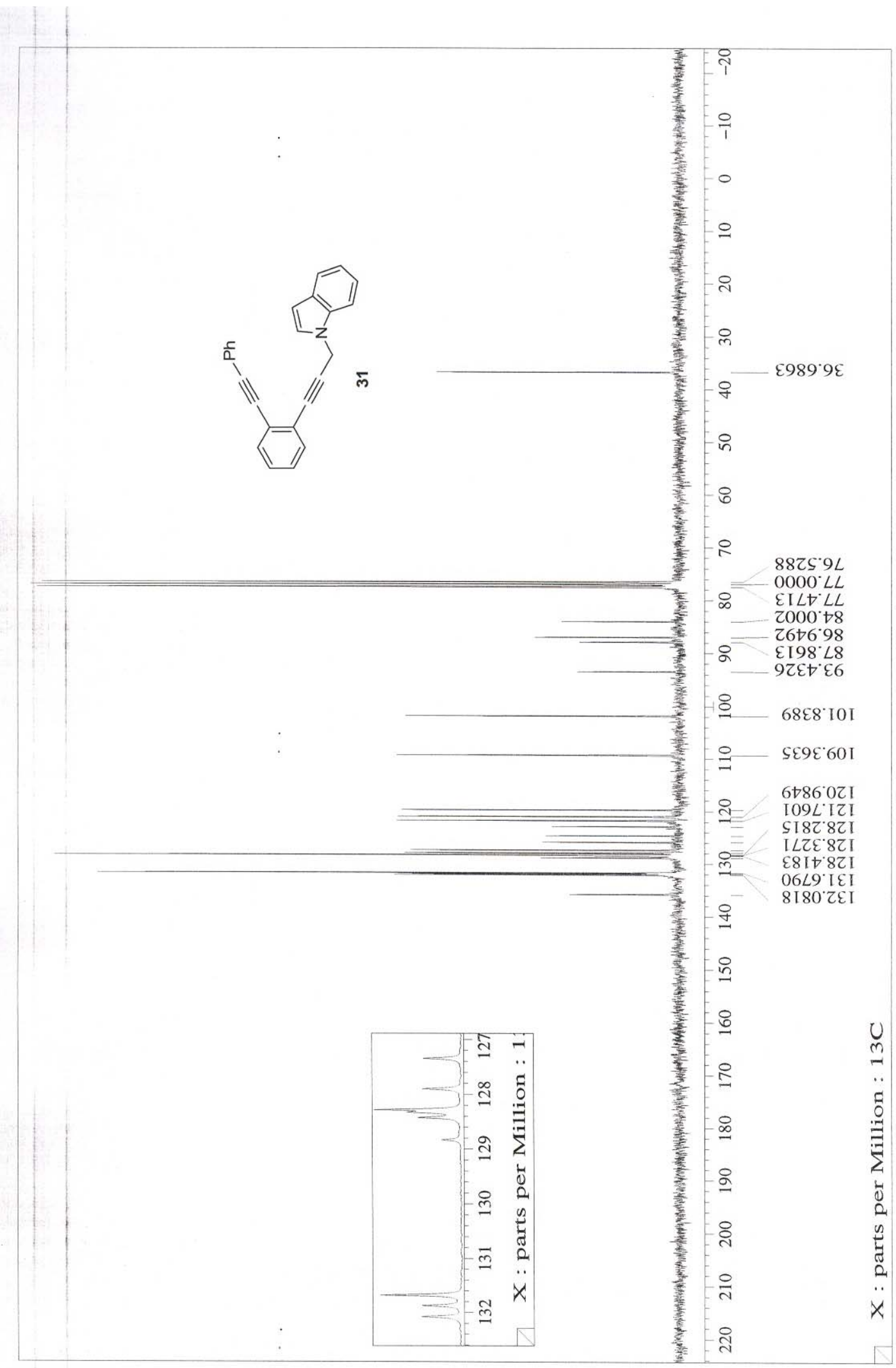




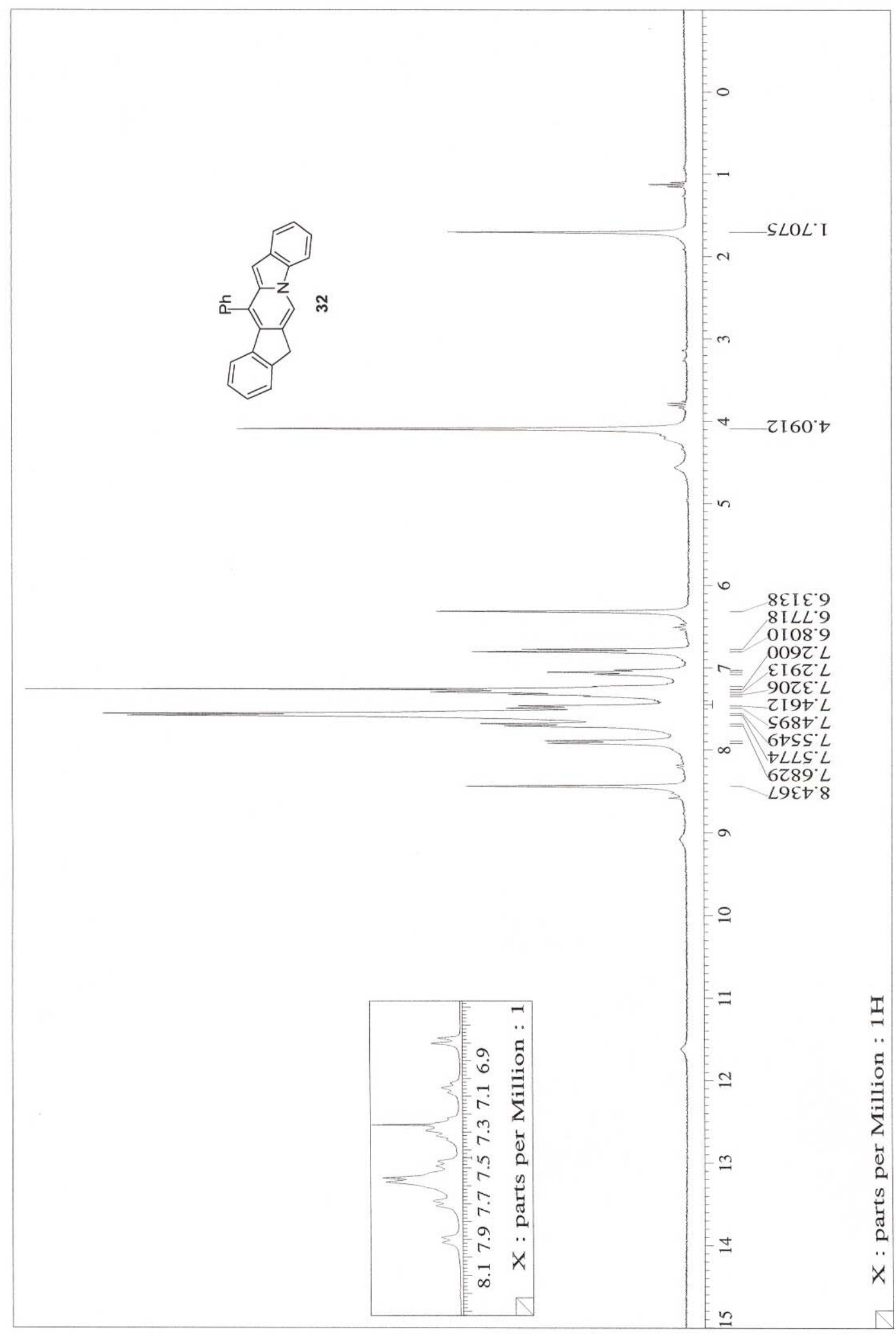




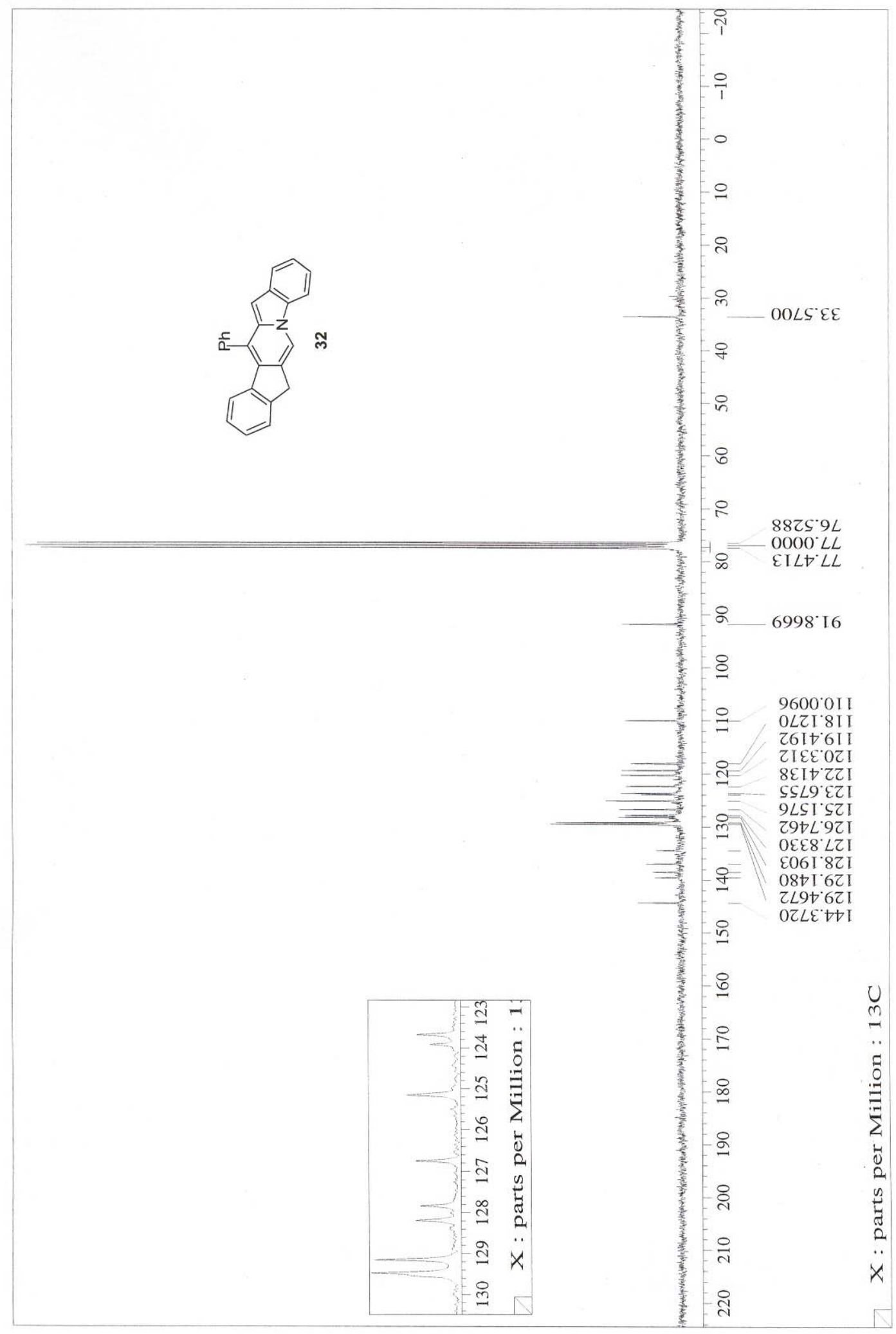




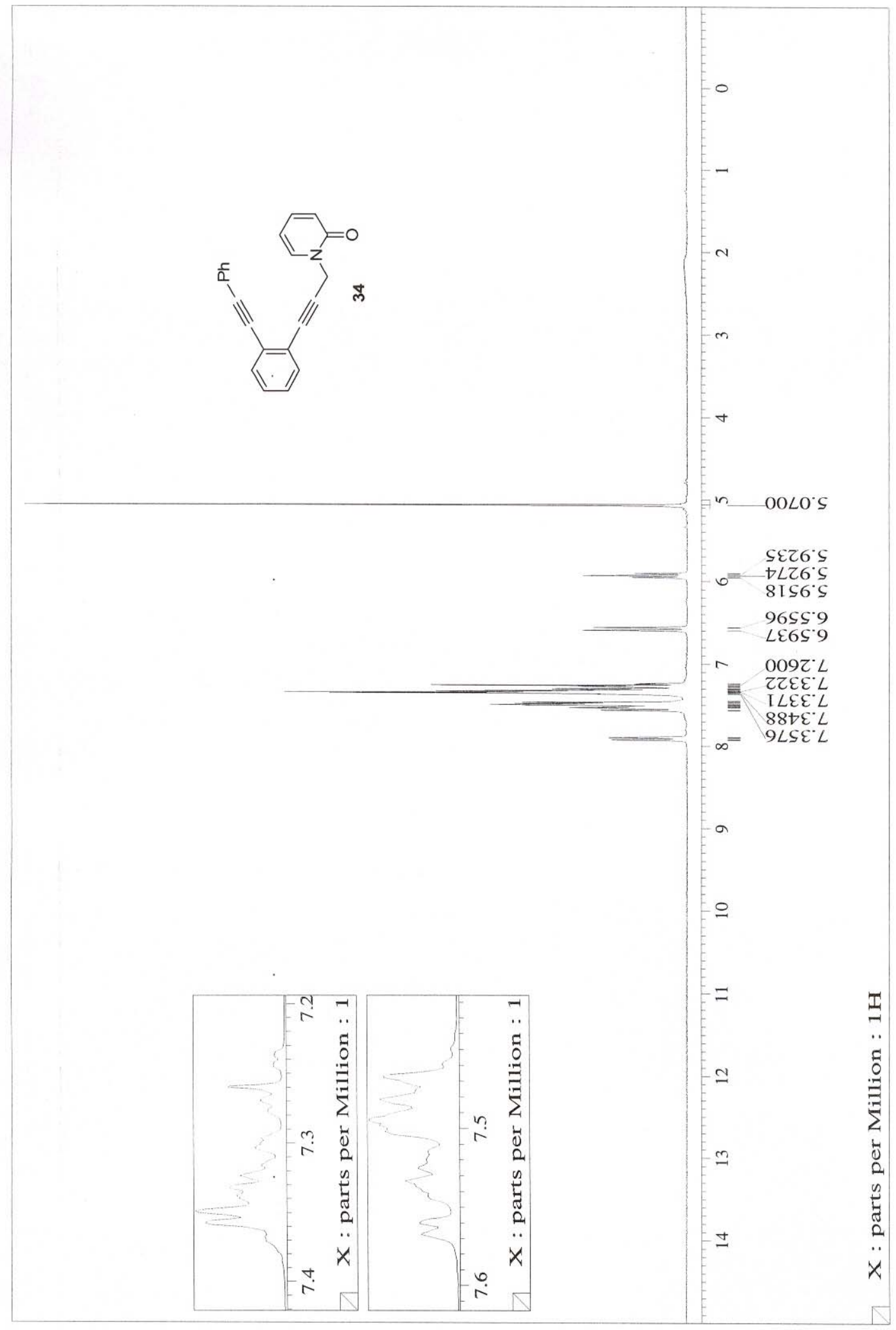




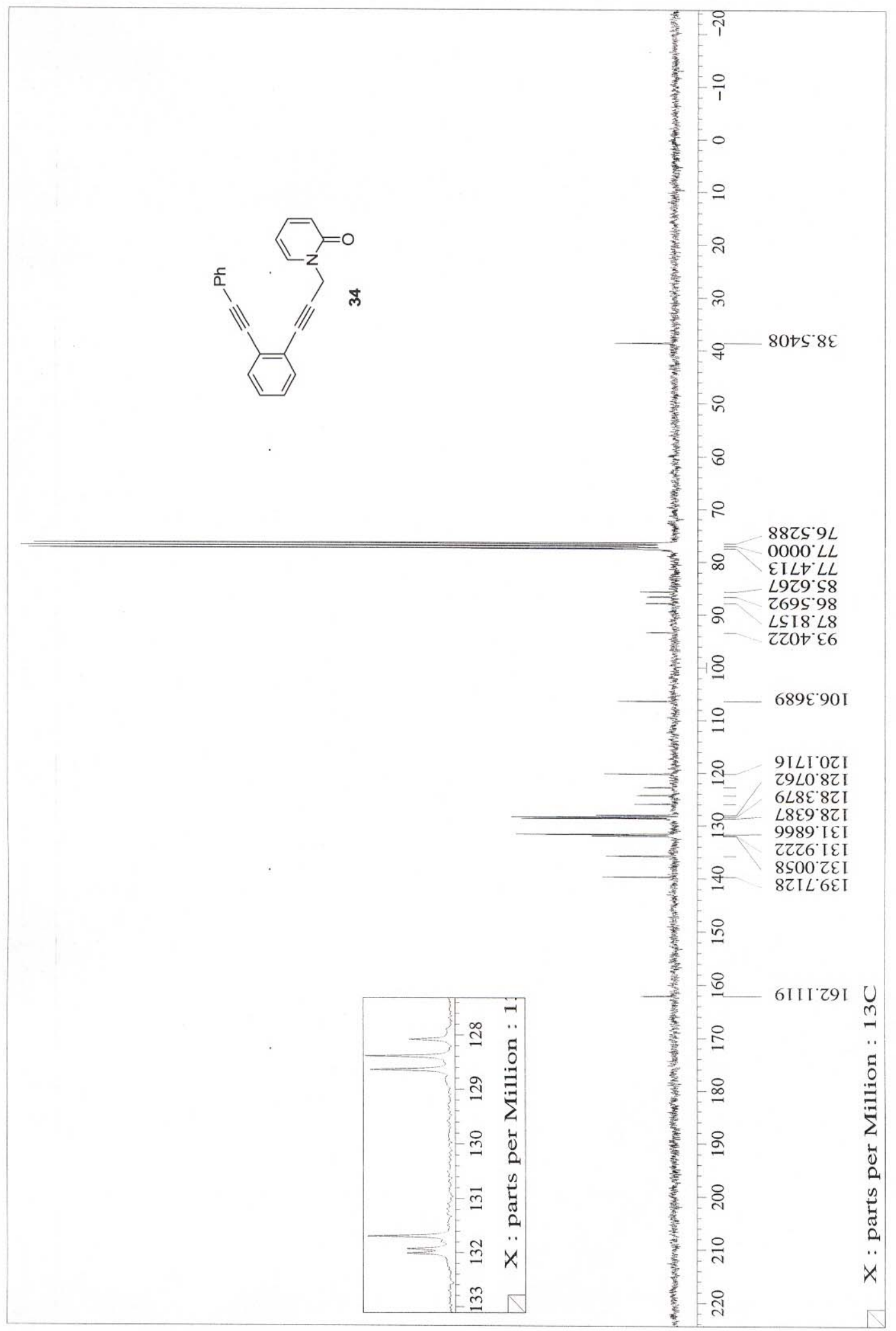




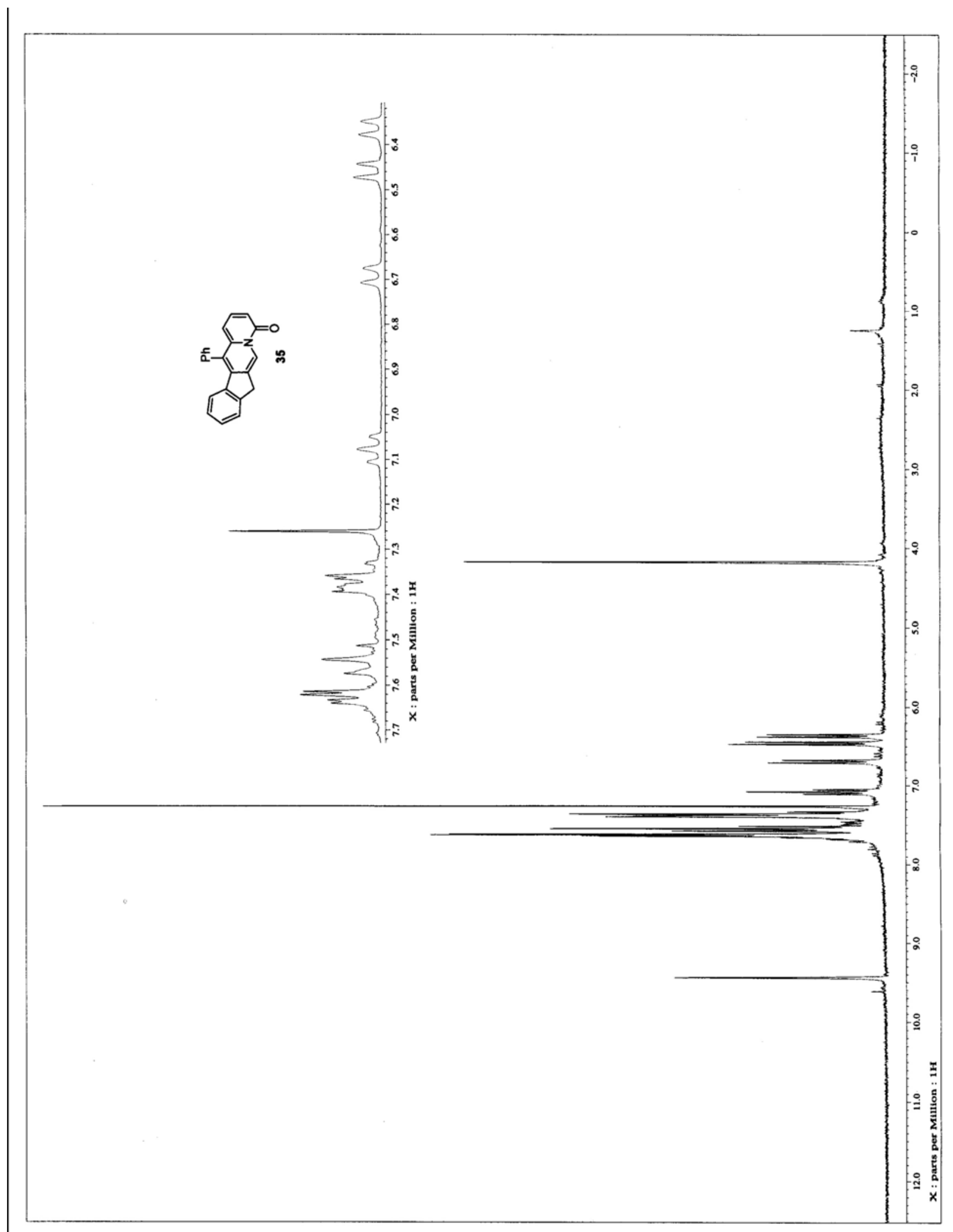




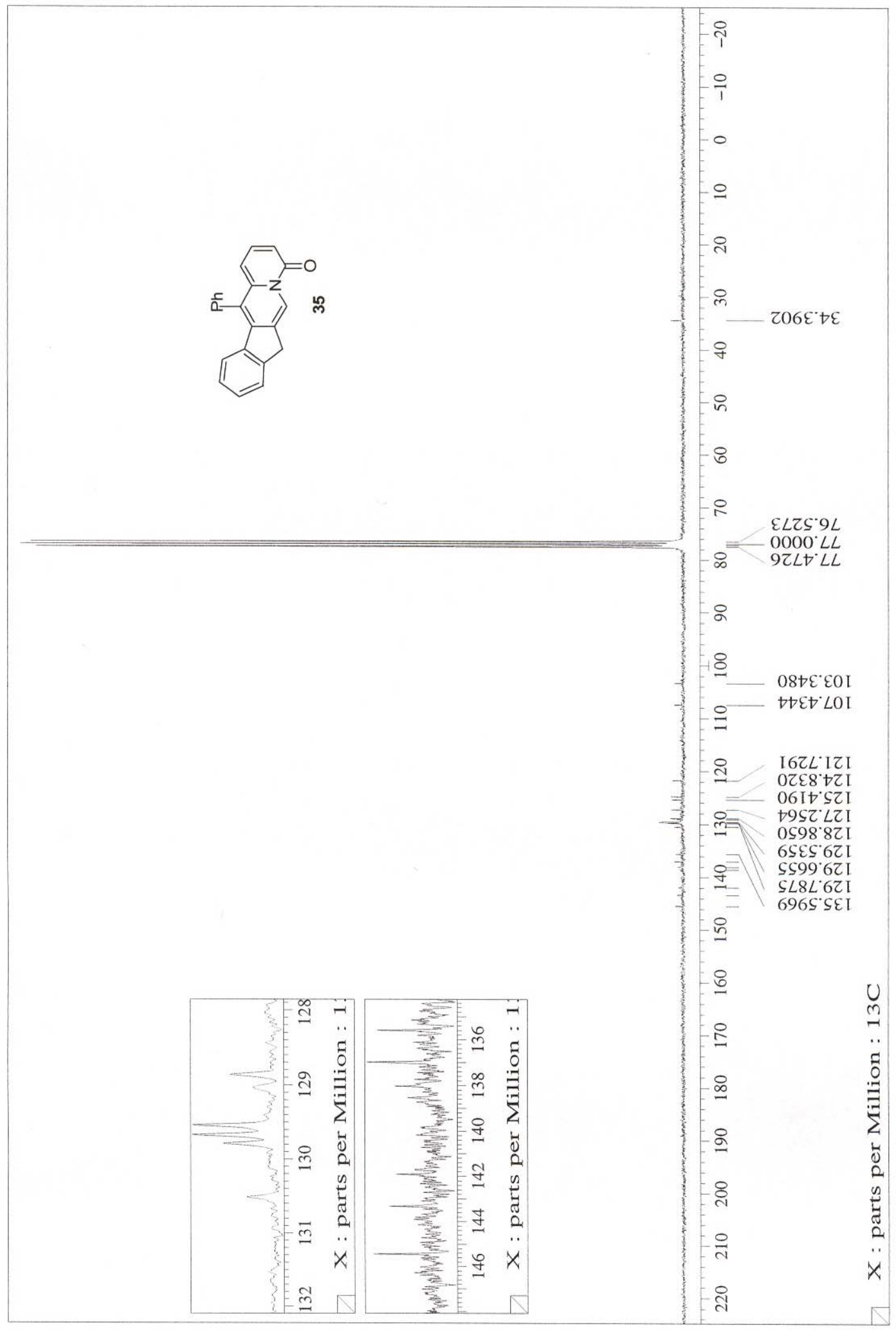




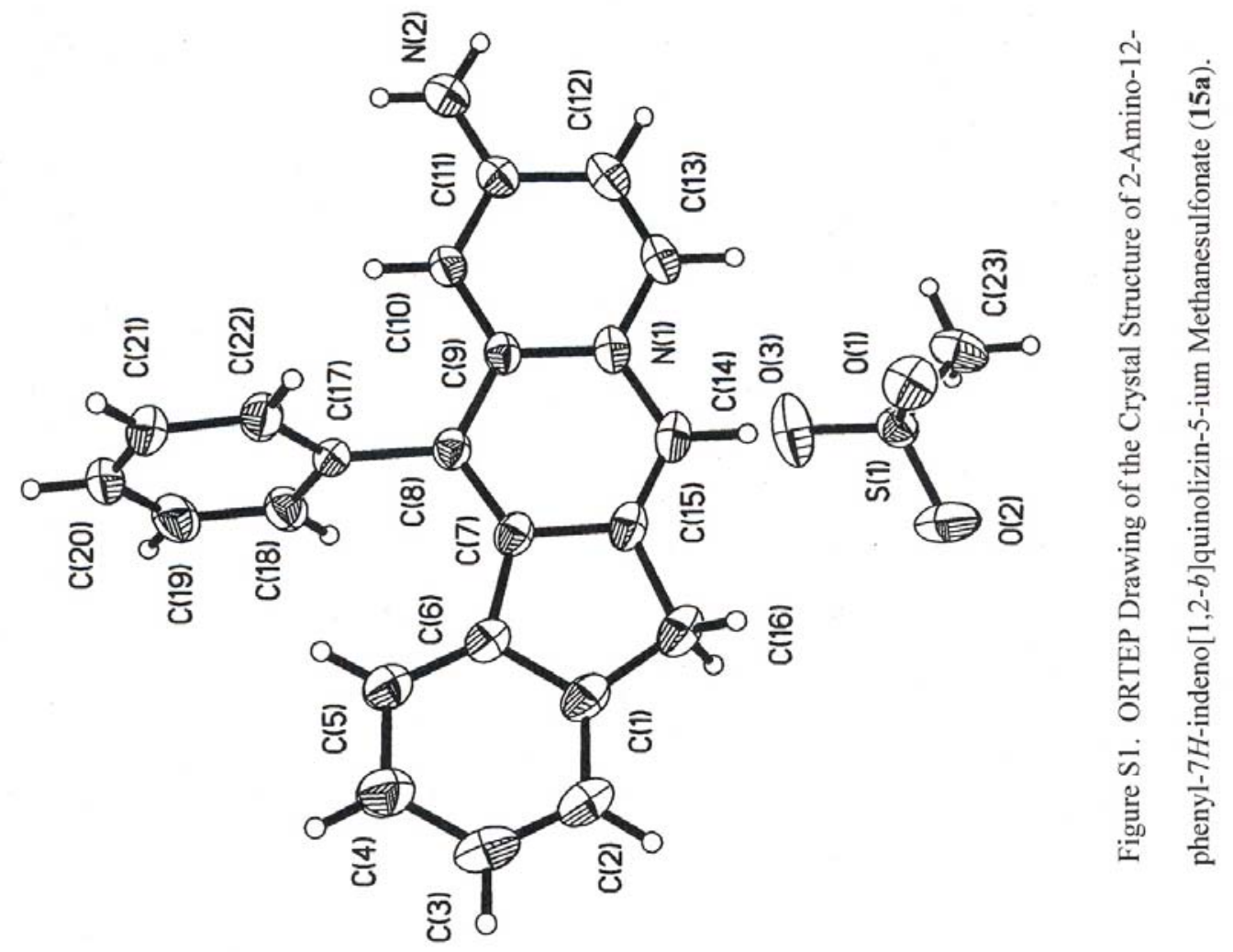




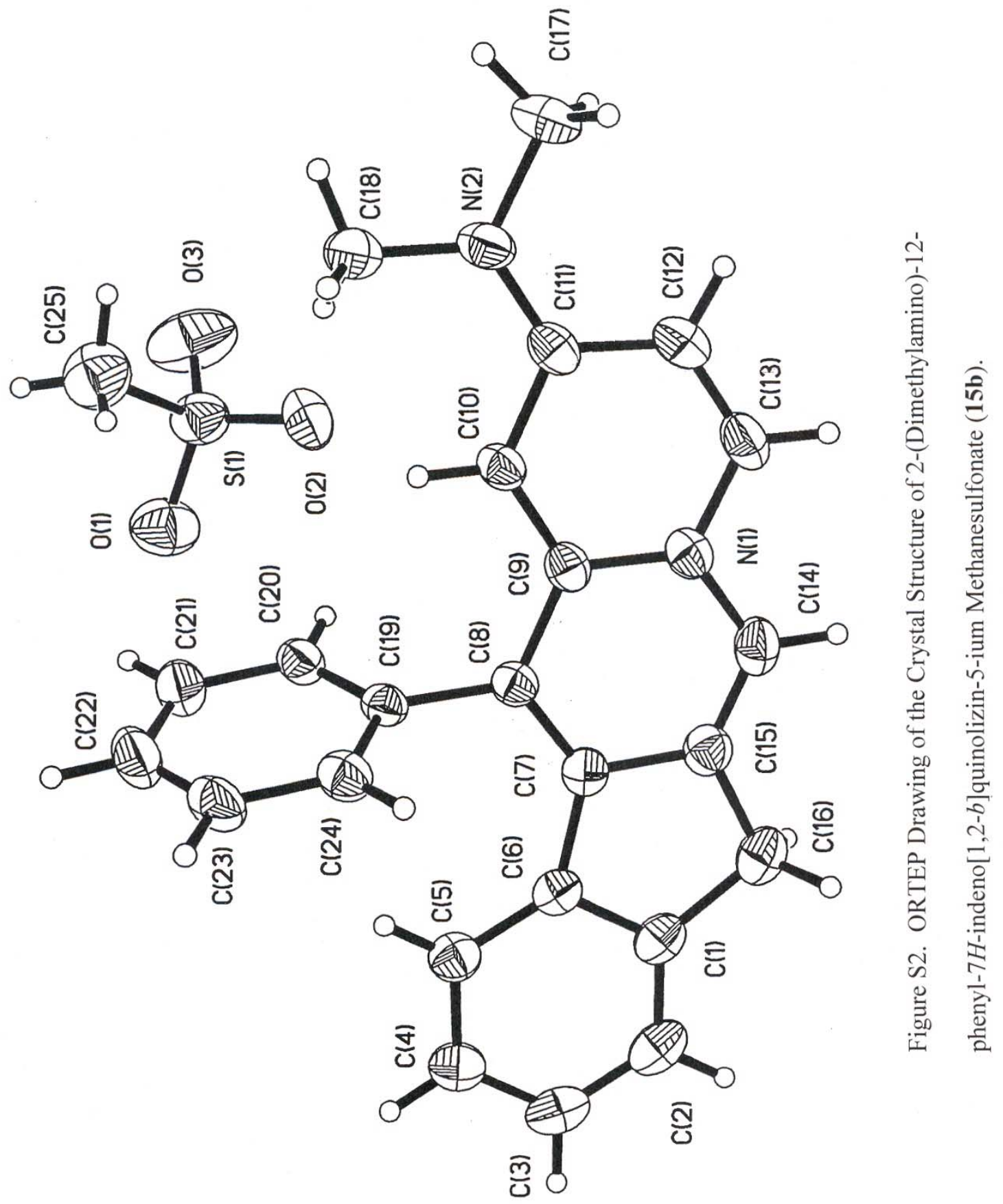




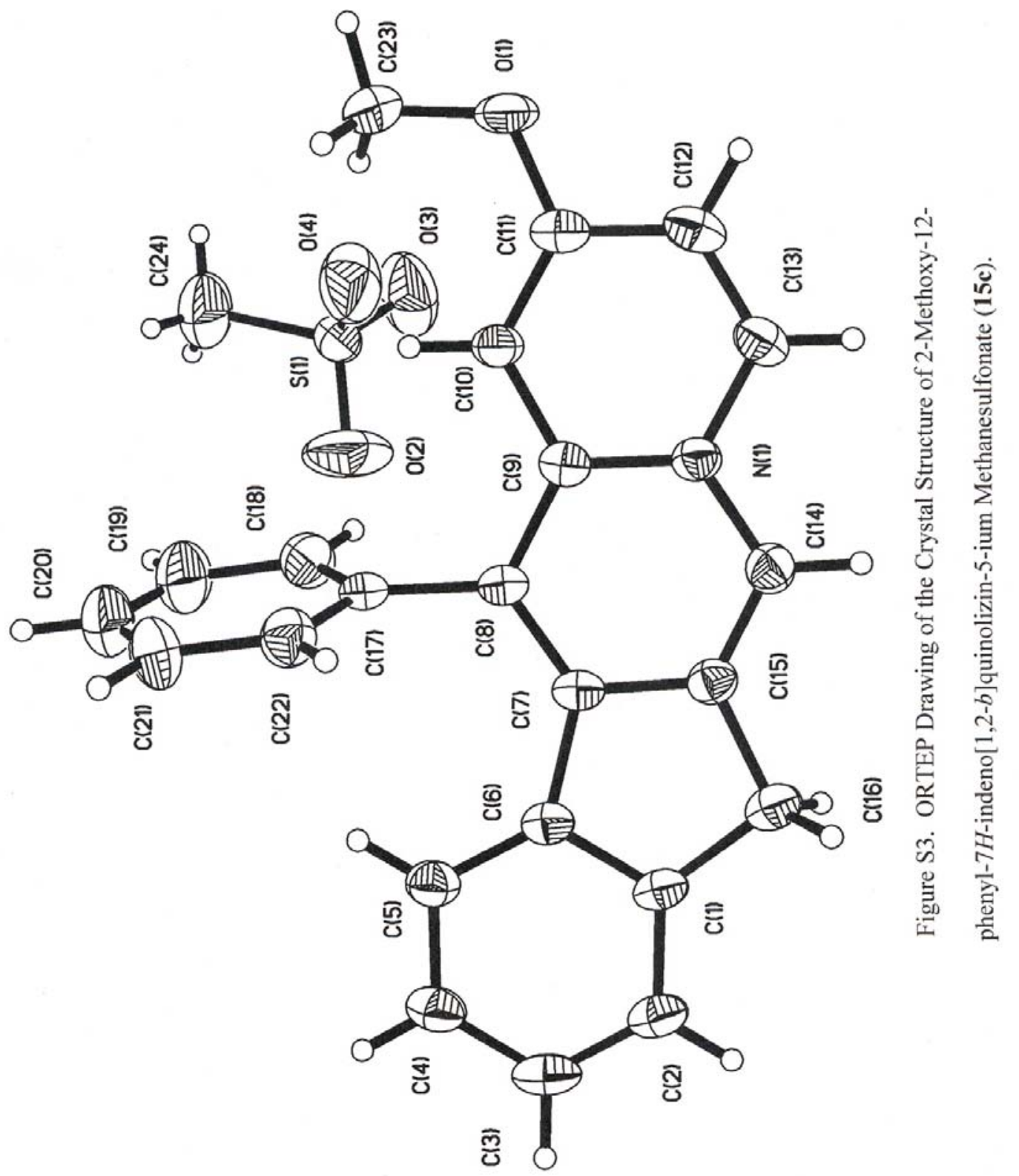




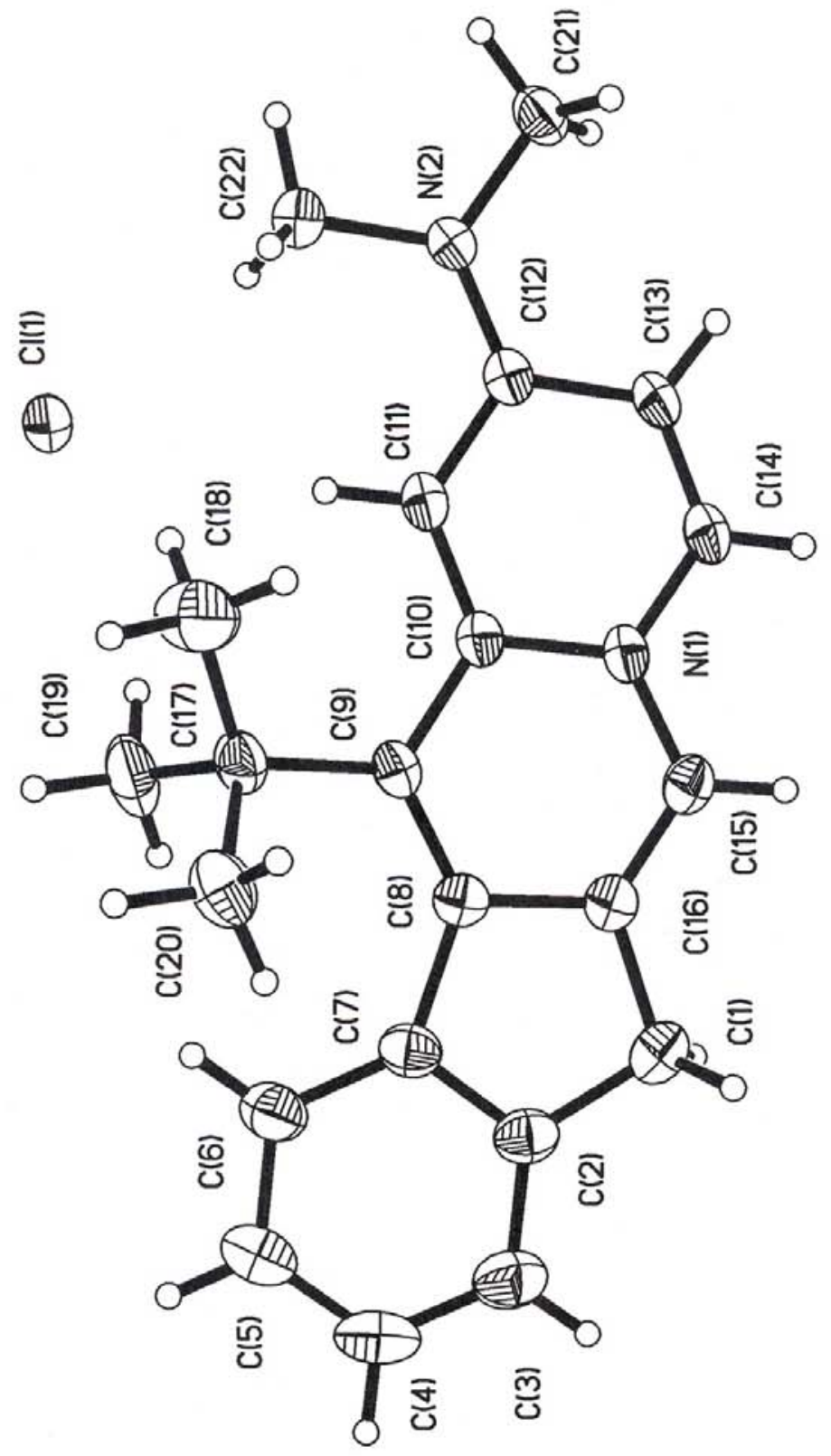

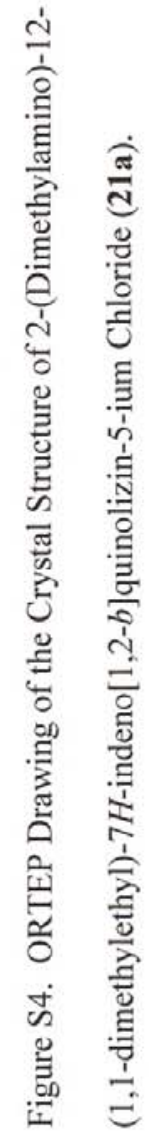




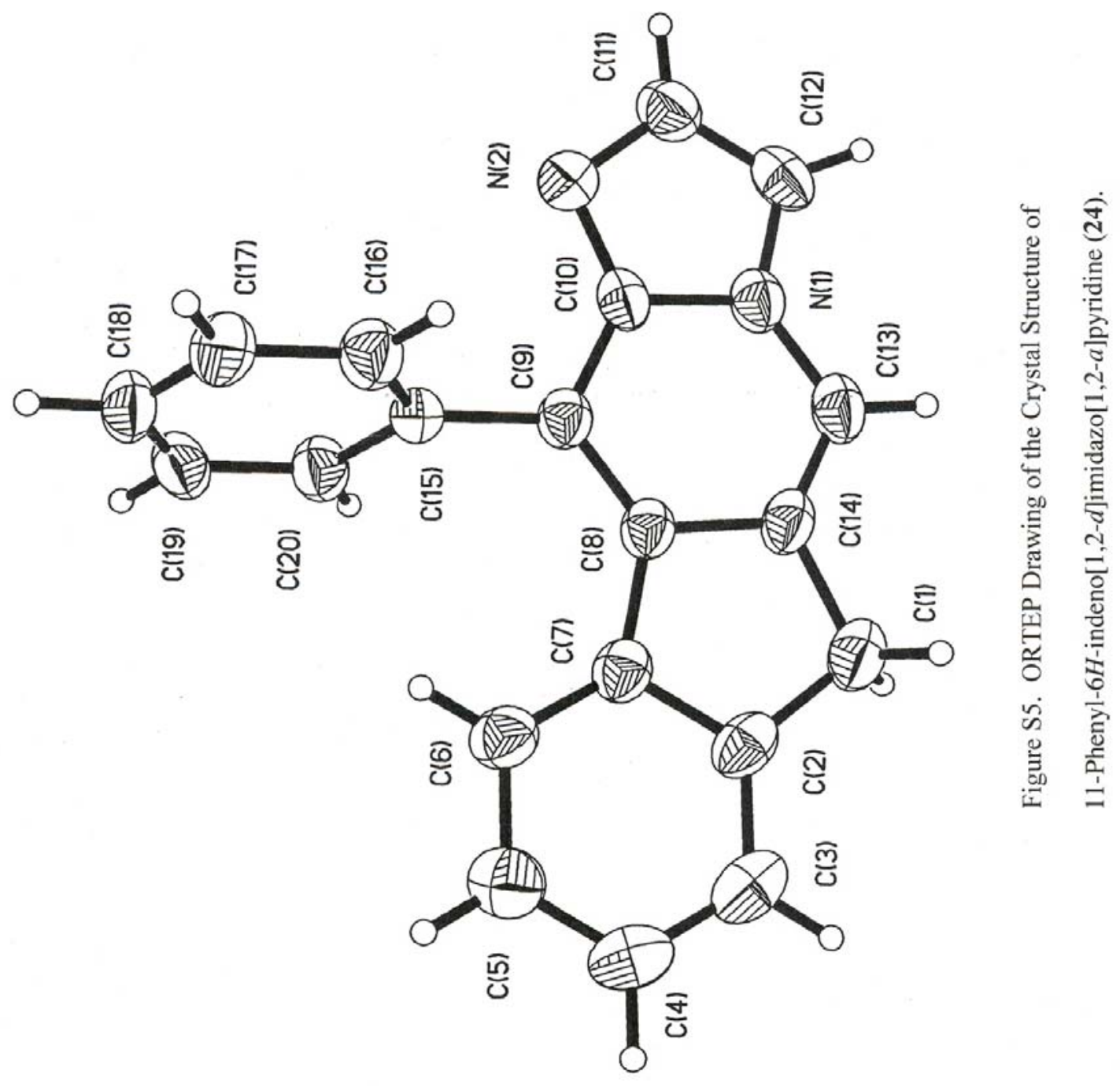




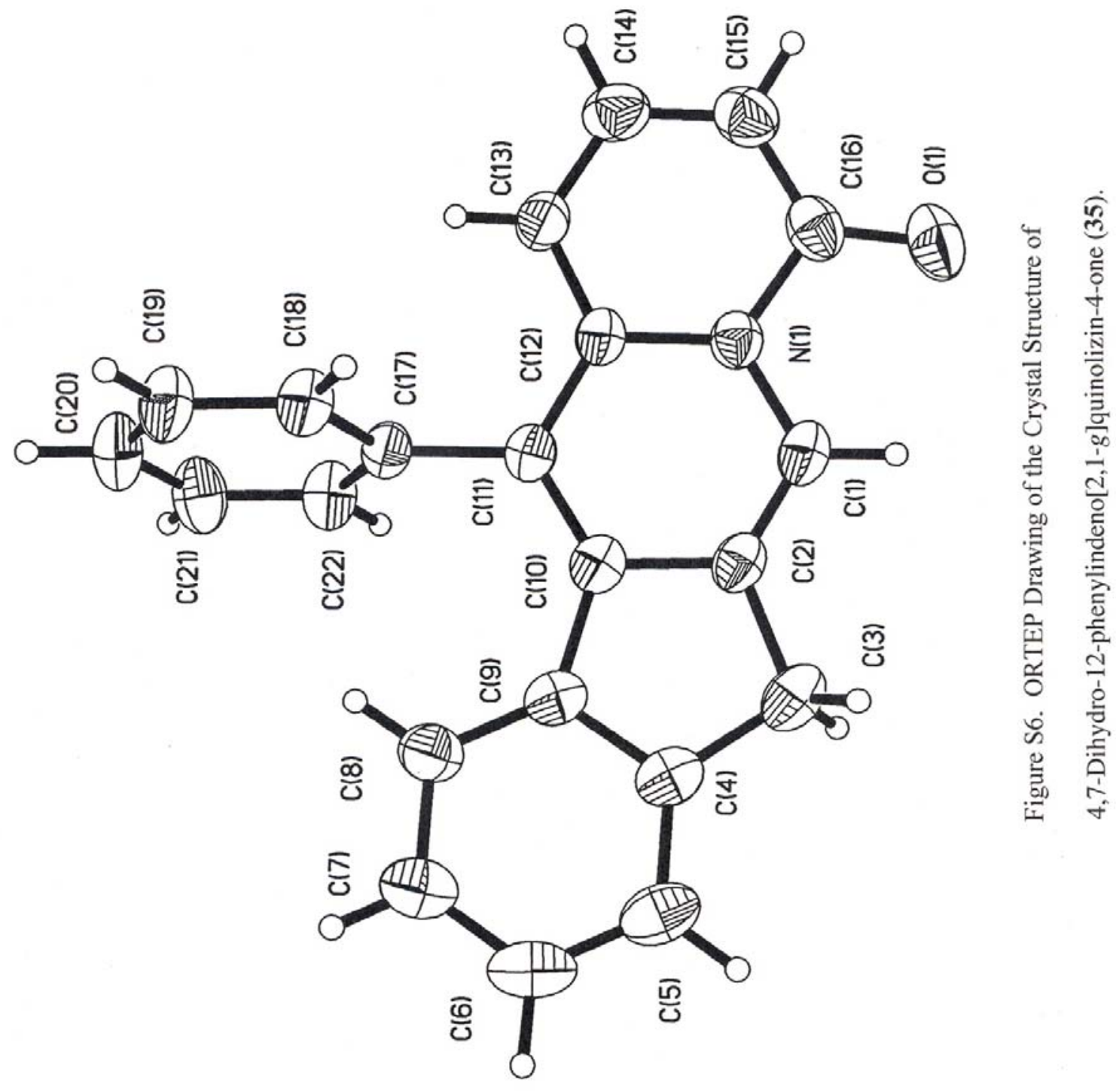

